\title{
Application of technology assessments to co-learning for regional transformation: a case study of biomass energy systems in Tanegashima
}

\author{
Yasunori Kikuchi $^{1,2} \cdot$ Miwa Nakai $^{1} \cdot$ Yuichiro Kanematsu $^{1} \cdot$ Kazutake Oosawa $^{1,3} \cdot$ Tatsuya Okubo $^{1} \cdot$ Yuko Oshita $^{2,4}$. \\ Yasuhiro Fukushima ${ }^{5}$
}

Received: 5 February 2019 / Accepted: 16 March 2020 / Published online: 28 March 2020

(c) The Author(s) 2020

\begin{abstract}
Japan is faced with sustainability challenges such as resource security and depopulation. Well-coordinated, multifaceted actions including a shift from imported fossil to locally available renewable resources and empowering of rural areas are vital in tackling these challenges. Here, we present our co-learning approach to practice the multifaceted actions with a case study on Tanegashima, an isolated Japanese island. In these actions, thorough understanding of the feasible technologies, the locally available resources, and the socioeconomic aspects of the local community should be shared among the stakeholders to acquire the momentum for a change. In addition to the technoeconomic analysis, several other analyses were conducted to reveal the concerns of respective stakeholders, share the understandings on the possibilities of technology options, and their socioeconomic implications on local sustainability. Tools such as the life cycle assessment, input-output analysis, and choice experiments based on questionnaire surveys on the residents' preferences are used for the analyses. The stakeholders were provided with the results during a 5-year period, through more than 30 co-learning events, e.g., symposiums, seminars, and workshops. A total of ca. 1400 participants from residents, local industries, public organizations, and a high school joined these events. These opportunities gradually converted the concerns of the local stakeholders on their future regional energy systems into expectations and yielded constructive alternatives in technology implementation that can use the locally available resources. The changes in residents' mind set through the co-learning processes induced by the contributions of the outsiders, providing professional insights acquired from the analyses and through the interactions with local stakeholders were examined in this study. This study demonstrates that the holistic incorporation of scientific technology assessments into co-learning can help coordinate the collaboration between researchers and local stakeholders toward regional transformation.
\end{abstract}

Keywords Life cycle assessment $\cdot$ Input-output analysis $\cdot$ Structural path analysis $\cdot$ Choice experiment $\cdot$ Sugarcane $\cdot$ Biodiesel

Handled by Yoshiki Yamagata, National Institute for Environmental Studies Center for global environmental research, Japan.

Electronic supplementary material The online version of this article (https://doi.org/10.1007/s11625-020-00801-1) contains supplementary material, which is available to authorized users.

Yasunori Kikuchi

ykikuchi@ifi.u-tokyo.ac.jp

Extended author information available on the last page of the article

\section{Introduction}

Japan is at a momentous turning point as it faces a wide range of social issues induced by universal trends (Komiyama 2014), i.e., the advanced maturity of the population and severe limitations in acquiring resources. In particular, the shift from fossil to renewable primary energy resources calls for proactive solutions for transformation toward a circular economy equipped with sustainable energy systems. The empowerment of rural regions has become a nationwide project in Japan, which are at the frontier of social issues including vulnerable energy system. Characteristics 
connected to biomass resources and rural areas, such as Satoyama and Satoumi, should be used as means to confront sustainability challenges at the local community toward revitalization (Wiek et al. 2015), because agriculture, forestry, and fishery are crucial to sustainability among many industries (Kajikawa 2008). Policies at a national level have been enacted to promote regional revitalization by means of a subsidy for local governments to revitalize their local economies (Cabinet Secretariat 2014, 2015). However, the incentives induced by these policies are insufficient in creating enough momentum within the regional societies due to the lack of knowledge, skills, and funds and the absence of appropriate human resources to drive the envisioned transformation.

Novel technologies, including processes, systems, and ways of thinking, are expected to play a critical role in transforming regional societies to become revitalized and sustainable. Technology brokering should be addressed for better implementation of technologies (Hering 2016). However, technology development has the "valley of death" in the transfer to society, as is often seen for various energy technologies (e.g., Weyant 2011). Many types of subsidies are designed to bridge the valley by accelerating technology development based on the technology readiness level (e.g., Debois et al. 2015). The feed-in tariff on renewable power sources started in July 2012 in Japan, resulting in a sharp increase in the development of photovoltaic (PV), wind turbine (WT), geothermal, and biomass technologies, and particularly in PV penetration (ANRE 2018). However, the public may perceive that an insufficiently mature technology, or the new installation of existing technology even if it has previous implementation examples in other regions, could have unpredicted consequences associated with its implementation in their regional societies, resulting in the creation of a difficult obstacle to overcome for innovative change in social systems (Weyant 2011). Especially in energy-related technologies that mitigate fossil resource consumption, decentralized and multiple-generation technologies are often seen as promising, but the barriers in progressing to demonstration tests are often too high, hindering the implementation of such technologies. Although technology road-mapping has become a method to address such obstacles by making the effects of technology implementation qualitatively or quantitatively transparent (e.g., Kato et al. 2016), technology road-mapping has limited roles in practical technology implementation.

Comprehensive engagement of regional players such as local governments, public organizations, nonprofit organizations, industries, and citizens is pivotal to transdisciplinary research in sustainability science. Among various scholars on the transdisciplinary modes, the co-design of research agendas and co-production of knowledge with stakeholders have been advocated to help achieve global sustainability (Future Earth 2013). Co-design is defined as a process in which "the overarching research questions are articulated through deliberative dialogs among researchers and other stakeholder groups to enhance the utility, transparency, and saliency of the research" (Future Earth 2013). Although co-design can become an important process for public engagement in transdisciplinary research in sustainability science, some challenges have been recognized before further transdisciplinarity in the co-production and co-delivery of knowledge (Sugiyama et al. 2017). Especially, the less agreement of values and relevance induced by research activities (Jahn et al. 2012) can disturb some stakeholders regarding their low relevance and potentially conflict with their own interests (Sugiyama et al. 2017) while the knowledge exchange is one of the key drivers for regional development (Lutz et al. 2017). Research on sustainability transitions needs to move from intensifying conflicts to co-learning between transition pathway narratives (Luederitz et al. 2017). Co-learning can generate an open atmosphere in which everyone can participate in defining the issues and seeking alternative solutions for the future (Francis et al. 2011) to be ready to leave their comfort zone (Hazard et al. 2018). All related groups involved in co-learning opportunities have differing perspectives on the engagement into decision-making based on their understandings of knowledge, values, and preferences regarding local issues (Lynam et al. 2007), obtained from multiple sources of information and stimulation (Francis et al. 2011). According to Gillson et al. (2019), co-learning is a key process to achieve decision-making when socially complicated factors are more dominant in a problem such as biodiversity conservation than technically complicated evidences. Co-learning has a role in fundamentally facilitating the steps of the co-creation of knowledge that fosters integrated research work across scientific disciplines, regions, and societal groups (Mauser et al. 2013). In addition, the co-learning paradigm can refine the matching of technology options to the actual circumstances of people and targets through integrated assessments on the effects of intervention (Coe et al. 2014). Citizens' actions through co-learning can transform behavior in more integrative and effective ways (Kythreotis et al. 2019) of knowledgeable stakeholders in information society requiring innovative and interactive transdisciplinary scientific approaches (Bouma 2014).

In this study, we address the social embeddedness of energy technology options through the holistic application of scientific technology assessments into co-learning. The main questions in this study are whether systematic technology assessments could contribute to the bridging of the valley of death between research development and 
actual implementation, how the settings of assessment, i.e., boundary, indicators, and raw data, could be defined through co-learning for mitigating regional concerns, and how the assessment results could become informative for regional stakeholders to understand the necessity of the implementation of the technology options. A case study was conducted on the implementation of decentralized biomass energy systems into practice on Tanegashima, an isolated Japanese island. Decentralized biomass energy systems can effectively utilize locally unused resources and require technology fitting with regional characteristics. While PV and WT can become stand-alone power sources, biomass systems require collaborated works to maintain cultivation, transport, and utilization. To address such required collaboration, co-learning among stakeholders and researchers is adopted as the strategy for public engagement supported by multiple technology assessments. The energy systems on Tanegashima suffer from the increasingly apparent vulnerability in supply and demand chains. To address this issue, energy system projects that utilize locally available renewable resources have been launched in recent years. These projects are conducted through collaboration among municipalities, public organizations, local industries, and external universities. To communicate effectively among the stakeholders, the effects of such technology implementation on the regional resources, energy, and capital flows induced, a co-learning of concerns and ideas among the stakeholders is of great importance. The target technology options in this study apply regionally available surplus bagasse from the cane sugar mill, woody biomass, and waste cooking oils to energy and fuel production. Several analyses were conducted based on co-learning opportunities to define their settings and provide the relevance of technology options against the concerns of stakeholders employing tools such as life cycle assessment (LCA) for environmental aspects, input-output (IO) analyses for the regional circular economy, and choice experiments based on questionnaire surveys on the residents' preferences for assessment of social aspects. More than 30 co-learning events, e.g., symposiums, seminars, and workshops, were held with a total of about 1400 participants from residents, local industries, public organizations, and a high school over a period of 5 years. In "Materials and methods", the co-learning with technology assessments in Tanegashima is shown with the introduction of case study, technology assessments applied in this study, and the functions of co-learning. The effects of co-learning with technology assessments are interpreted in "Technology assessments with co-learning for regional transformation" followed by a discussion on the embeddedness of co-learning and requirements for technology assessments and co-learning.

\section{Materials and methods}

\section{Co-learning with technology assessments in Tanegashima}

\section{Introduction to the case study: background and technology implementation projects}

Tanegashima is one of the remote Japanese islands where the social issues on energy security and depopulation have become more critical in comparison to most of the other areas (see also Fig. S1 and Table S1). Especially in energy systems, the vulnerability in supply and demand chains has become critical to maintain the performances of the systems. Tanegashima has independent electricity grids from four main Japanese islands. The power mix is mainly composed of diesel engines, the power generation costs of which are much higher than the other areas on the four main Japanese islands due to the transport of fuels from the oil refineries on the main islands and technical staff for maintenance. It resulted in the deficit production of power by power company at Tanegashima. Recently, renewable power sources were forced to cut their power outputs interconnected to the Tanegashima power grid (KEPCO 2018), because the capacity of following intermittent power loads had been decreased by the decrease of power demand and the increase of PV power generation, which can lead to the fluctuation of power frequency. Note that the laws and regulations on energy systems are also changing in Japan. For example, the feed-in-tariff for renewable power sources was incorporated into the electricity market in July 2012. The retail sale of electricity in Japan was opened to new entrants in April 2016. The separation of electrical power production from power distribution and transmission will be completed in 2020.

Several energy system projects have been launched on Tanegashima. The cane sugar mill can produce power and heat for the regional energy systems using surplus bagasse (Ouchida et al. 2017) and available woody biomass (Kikuchi et al. 2016a). A cultivar bred for combined sugar-ethanol production can increase their productivity. Selective fermentation has the role of improving the extraction efficiency of sucrose as food and supporting the implementation of high-yielding sugarcane (Ohara et al. 2012, 2018; Fukushima and Ohara 2018). The first demonstration process was constructed, operated and simulated (Kikuchi et al. 2017c) at the Tanegashima cane sugar mill for collecting data on sugar production intensified by ethanol production. Woody biomass can also be used as the fuels in combined heat and power (CHP) production, considering the available timber supply on Tanegashima (Kanematsu et al. 2017a). Technology demonstration of 
an ion-exchange resin-catalyzed process for biofuel production from waste cooking oil was also conducted. This technology had been developed in academia as a next-generation process for biodiesel production with high conversion ratio and low impurities in the biodiesel fuel product (Shibasaki-Kitakawa et al. 2010, 2013). The process was validated in a pilot-scale process established at a university (Shibasaki-Kitakawa et al. 2016). Industrial-scale plants have been constructed on Tanegashima to verify the applicability of the ion-exchange resin-catalyzed process in society (Chen et al. 2017) (see also supplementary material for details of this technology).

\section{Systematic technology assessments for biomass energy technologies}

The possible technology options are adequately examined and recognized from the perspective of sustainability science as embraced by conventional natural and social sciences (Komiyama and Takeuchi 2006) for catalyzing the learning process (Fukushima et al. 2017). The relationships between society, economy, and technology must be understood in the context of the target region. These elements of technology assessment for biomass energy technologies are schematically represented in Fig. 1 as spheres related to technology implementation, as discussed by Geels (2006). All spheres are parts of the biosphere or ecosphere, including natural ecosystems such as climate and resource circulation. These spheres have been recognized as the interfaces of transdisciplinary research to frame the actual situation for implementing novel factors, such as marketing natural environments (Neace 1995), entrepreneurship ecosystems (Frederick 2011), and interpretation of quantified environmental impacts by LCA (Hofstetter 1998).

The relationships among these spheres were taken into account for co-learning by technology assessments based on research examples related to biomass-derived production. Economic aspects of technology implementation have been examined in technoeconomic analyses to clarify the relationships between the characteristics of technologies and various economic indicators, such as direct and indirect costs, fixed capital investment (e.g., Liew et al. 2014), and product price (e.g., Ilic et al. 2014). Socioeconomic analysis has also become an essential method for analyzing the impacts of technology and can be a driver for implementation (Domac et al. 2005). Ji and Long (2016) summarized

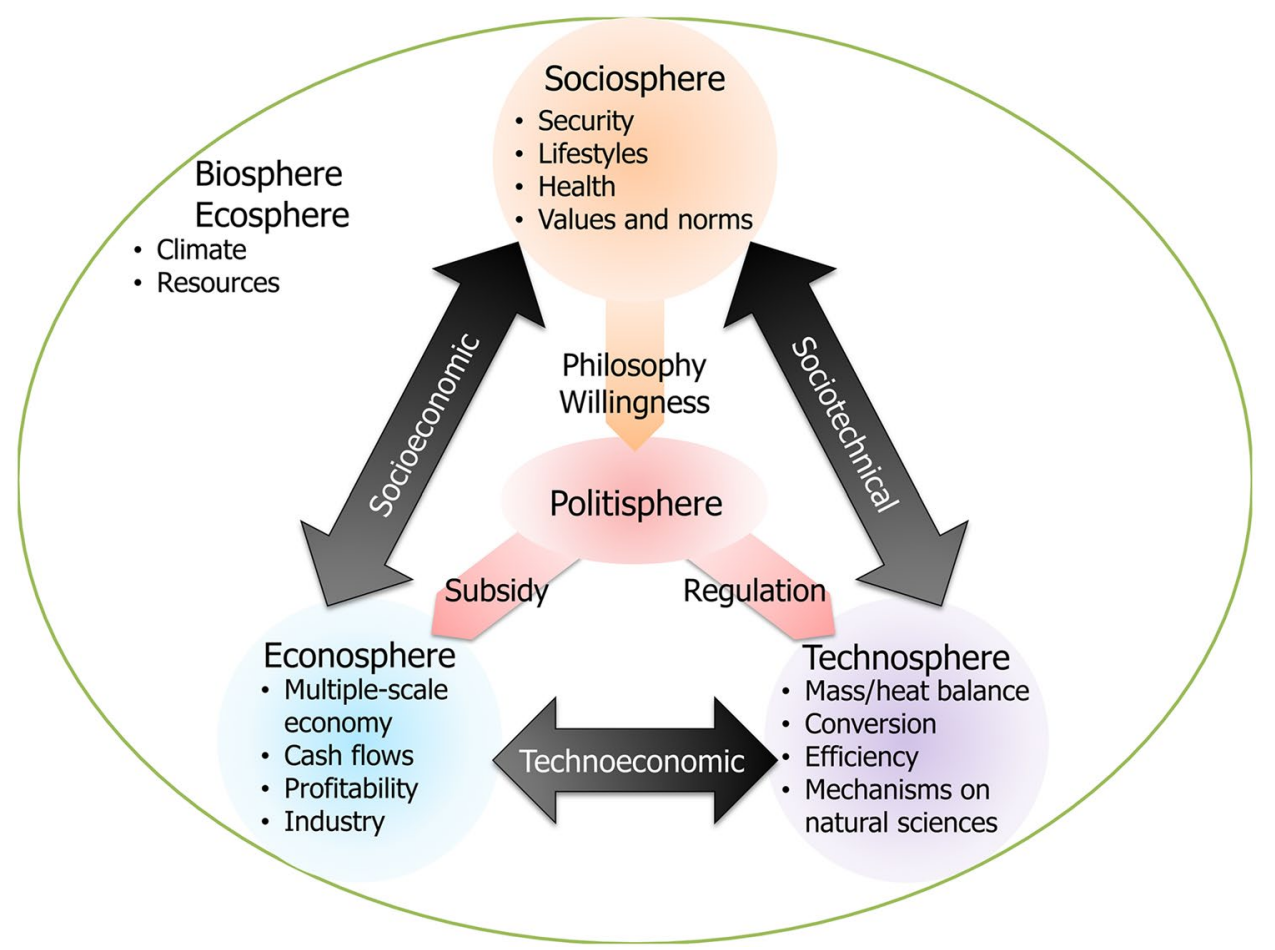

Fig. 1 Elements of technology assessment for regional transformation represented as spheres related to technology implementation. The sociosphere contains the social systems and their philosophies, such as security, lifestyles, and health motivations. The econosphere is composed of industrial, regional, national, and global economies represented as their cash flows based on industrial activities. The technosphere contains technology-based systems represented as mass or energy balances based on their conversion efficiency originating from the mechanisms of natural sciences. The politisphere can be related to all other spheres by considering the philosophies and willingness of the sociosphere, supplying a budget as the subsidy to circulate the economy, and regulating the activities in the technosphere based on public benefits 
the current studies on the socioeconomic effects related to biofuels under income, employment, food security, and economic cost by addressing not only feedstock, conversion, and opportunity costs but also the loss of land value caused by pure-energy crops. Festel et al. (2014) decomposed the price of biofuels in comparison with the prices of crude oil and considered other major drivers, including global population and growth in wealth, as indicated by gross domestic product and global inflation. The benefits should be analyzed within a sociotechnical approach to ensure that society benefits from the implementation of the technologies. In microcommunities, the social aspects are essential for renewable energy systems (Neves et al. 2014), and the quantification of which can be conducted partly by contingent valuation methods, such as the willingness-to-pay (WTP) (Stigka et al. 2014). Sociotechnical research can provide broader feasibility checks on the outcome of technologies for stakeholders (Geels et al. 2017; Grunewald et al. 2012).

\section{Functions of co-learning opportunities in Tanegashima}

Co-learning in this study is an opportunity to exchange the information for and from technology assessments. The concerns of regional stakeholders were taken into account in the settings of technology assessments. For example, the system boundaries of LCA and IO analyses should contain the concerned processes within Tanegashima such as farming areas and regional industrial processes with actual efficiencies and foreground inventories. The scenarios were defined on their applicability in Tanegashima. The questionnaires were also set for Tanegashima-specific availabilities of resources. These settings were based on the exchanges of concerns and ideas of regional stakeholders or researchers. The sharing of assessment results from researchers with stakeholders was a kind of feedbacks to revise the settings.

For this purpose, more than 30 co-learning events, e.g., symposiums, seminars, and workshops, were held with a total of about 1,400 persons, including people from municipalities, local industries, and public organizations and high school students (for the details of opportunities, see Table S2). The concerns and anticipations of the region's insiders for regional energy systems were addressed by the effects of technology implementation to use the locally available resources through interactive analyses by outsiders where the researchers also learn the necessity of customization of their own technologies for actual implementation considering the regional cultures and conventions. Such interactive analyses facilitating the communication between engineers, researchers, players, and stakeholders were identified as the essentials of co-learning for the transformation of regions. These possibilities were used to design the vision and scenarios to mitigate Tanegashima's social issues. The participating insiders were men and women of all ages. Throughout these communications, the changes in residents' mindsets were examined.

\section{Technology assessments based on co-learning}

The target-applicable technology options in this study are summarized in Table 1. The previous technoeconomic (Chen et al. 2017, 2018; Ouchida et al. 2017) and socioeconomic (Kikuchi et al. 2018; Oshita et al. 2019) analyses on the technology options in Table 1 show the material, energy, and cash flows attributable to the technology implementations. The sociotechnical analysis (Kikuchi et al. 2017a) has clarified the consumer preferences toward energy to be used on Tanegashima. In this paper, the methods are introduced in the following sections to assess the technology options in Table 1.

\section{Materials and energy flows by LCA}

The material and energy flows were analyzed by LCA as adopted in the previous papers for the cane sugar mill (Kikuchi et al. 2016a), agricultural and industrial processes (Ouchida et al. 2017), and forestry (Kanematsu et al. 2017a) on Tanegashima. The primary role of analyzing material and energy flows is to clarify the changes in life cycle inventories associated with technology implementation. The available amount of sugarcane on Tanegashima can be increased by changing the composition of cultivated sugarcane cultivars through massive deployment of the relatively new sugarcane cultivar, NiTn18, which has partly been implemented on Tanegashima and is expanding its cultivation ratio. The concerns of the sugar mill over the increase of reduced sugar inside the sugarcane can be mitigated by the installation of selective fermentation (Ohara et al. 2012). The increased bagasse can be used as biomass-derived fuel. The material and energy input and output of agricultural and industrial processes were determined based on the existing model (Ouchida et al. 2017).

The bagasse boilers already implemented in cane sugar mills can be converted to solid biomass boilers with minor changes in their feeders and operational systems. The mixed combustion of biomass resources was considered in applying bagasse and wooden chips available on Tanegashima as fuels for raw sugar production, power generation, and molasses-derived ethanol production. During the sugarcaneharvesting period (December to April on Tanegashima), the fuel for the boiler is mainly bagasse, the excess of which is stored and combusted during the nonsugar seasons, mixed with wooden chips, for power generation. The surplus electric energy produced during the sugar season as well as the entire electric energy produced during the nonsugar season is sold to the Tanegashima power grid (see also Table S1 for KEPCO's power plants). 


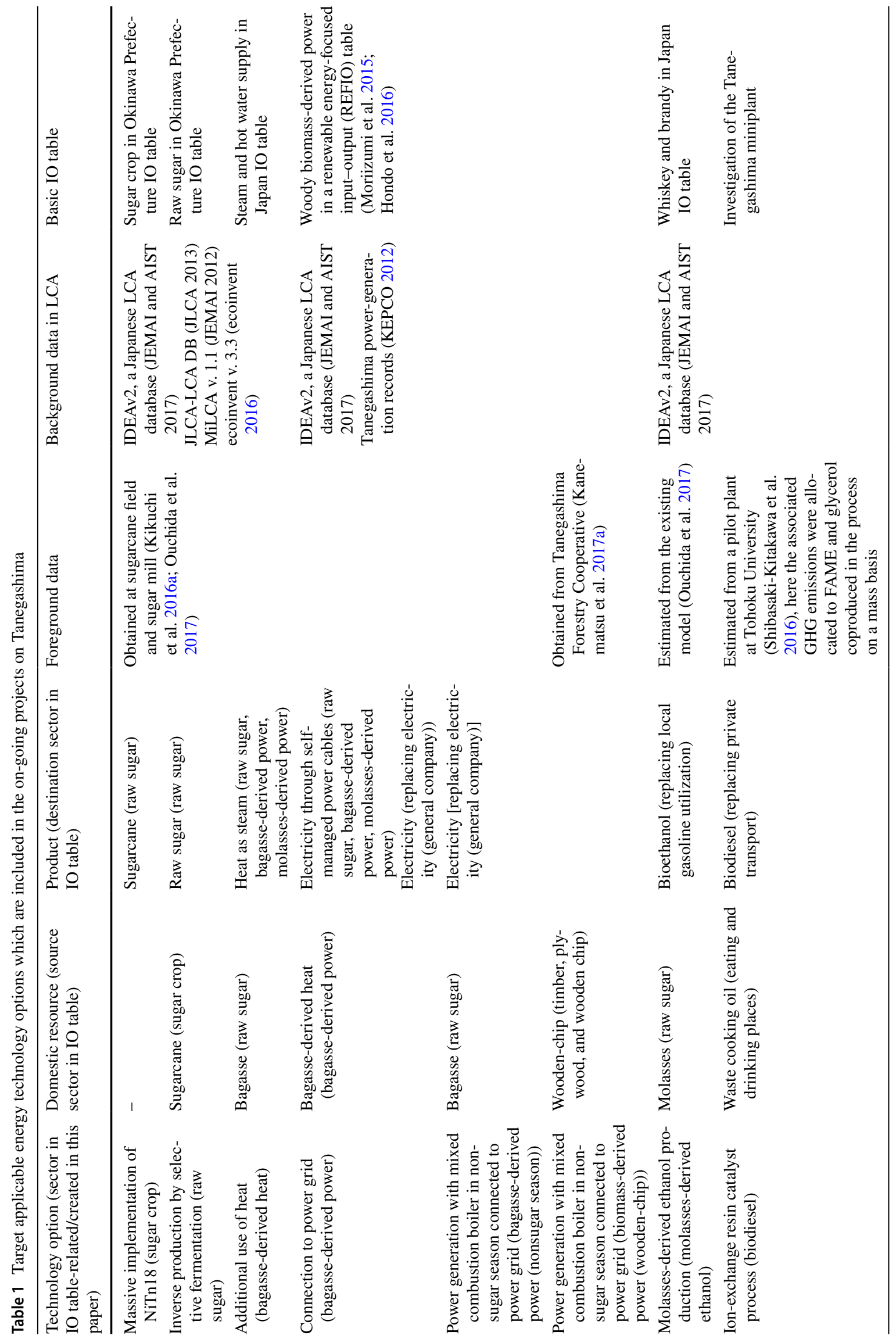


Biodiesel production is changing to the ion-exchange resin-catalyzed process from the conventional homogeneous alkali catalyst. Waste cooking oil was collected from $\sim 60$ restaurants from all over Tanegashima, which amounted to $\sim 22 \mathrm{~kL} /$ year. This same raw material is converted into biodiesel by means of a novel technology. The process inventory data for the collection and conventional production were obtained from actual records at the Tanegashima site, while the data for the novel technology were estimated from the operational records at the pilot plant in Tohoku University. The utilization of biodiesel was assumed to be the same as at present, i.e., for private transport such as for the workers and residents of welfare facilities on Tanegashima.

The material and energy data are used to conduct LCA to highlight the benefits of the transitions. Due to the geographical configuration, the transportation of resources to rural regions has to emit more carbon dioxide originating in the domestic transport from main Japanese islands. Therefore, in this paper, the greenhouse gas emissions from life cycles (LC-GHG) of energy technology options were adopted as the indicator for LCA, partly because the decarbonization of energy systems by locally available resources is an emerging opportunity not only on Tanegashima, but also all over Japan. The data collection for LCA was conducted as organized in Table 1.

\section{Cash-flow analysis by 10 table}

The role of the analysis of cash flow is to represent the internal and external Leontief's effects originating in the technology implementation listed in Table 1 . The flows can be visualized for products based on the structural path analysis (SPA) with an IO analysis (Kikuchi et al. 2017b) (see also supplementary material). Based on the SPA, the chains induced by the target products can be visualized as a cashflow structure. The ratio of the summation of all elements of the cash-flow structure to the annual production of the target sector is defined as the circulation index for measuring the effects of technology implementation on the cash-flow structure.

The Leontief's effects can be calculated from the customized IO table for Tanegashima (Kikuchi et al. 2018; Oshita et al. 2019). In Japan, IO tables have been prepared for the whole of Japan (Japan IO table hereafter) (MIAC 2010) and for individual prefectures. The structures represented in such large tables are the averages of industrial inputs, outputs, and demands, which cannot represent the specificities of the economic structures in small regions. For facilitating decision-making within regional transformation, customized IO tables accounting for the regional economic structures should be available. In this study, the non-survey method, using the IO table for the Kagoshima Prefecture (Kagoshima Prefecture 2010) as the base table, was basically adopted to create the basic economic structures, and Tanegashima's specificities were enhanced by applying the survey method. Some important sectors for Tanegashima were identified as independent sectors (see Table S3). The simulation-based estimations shown in the foreground columns in Table 1 were also connected to novel sectors created in the IO table (see also the supplementary material for details of the cashflow analysis).

\section{Residents' preferences for construction of effective narratives}

To motivate the players in regional systems, narratives should be carefully prepared to attract their attention and earn their positive preference for the regional transformation. Thus, surveys targeting Tanegashima residents were conducted to reveal their preferences towards the multiple attributes of grid power supply (Kikuchi et al. 2017a, b, c), i.e., detention surveys for Nishinoomote (survey 1) and Nakatane (survey 2) and a mail survey for Minamitane (survey 3) were used. Another survey was conducted for heating energy in Nakatane (survey 4), where the cane sugar mill is located and can provide the excess bagassederived heat through district heating and cooling (DHC) (Kanematsu et al. 2017a). The survey schedule is shown in Table 2. The questionnaires for surveys $1-3$ consisted of three parts followed by the properties of respondents, i.e., questions about the choice experiment, important factors for choosing electricity plans, and their preference to regional renewable resources for generating electricity. The questionnaire for survey 4 was similar to the abovementioned contents for the other surveys, but no choice experiment questions were included. The questionnaire comprised comprehension questions regarding CHP and DHC, the conditions for renewing hot water dispensers, regional renewable resources for local energy supply, and important factors for choosing energy for household
Table 2 Schedule and settings of surveys on Tanegashima

\begin{tabular}{llllr}
\hline Survey & Schedule & Method & Area & \multicolumn{1}{l}{ Responses } \\
\hline 1 & $2015 / 12 / 10-2015 / 12 / 22$ & Detention Survey & Nishinoomote & $729(77.1 \%)$ \\
2 & $2015 / 12 / 3-2016 / 1 / 31$ & Detention Survey & Nakatane & $231(40.6 \%)$ \\
3 & $2016 / 1 / 8-2016 / 1 / 31$ & Mail Survey & Minamitane & $334(34.7 \%)$ \\
4 & $2017 / 2 / 10-2017 / 3 / 31$ & Detention Survey & Nakatane & $2431(73.3 \%)$ \\
\hline
\end{tabular}


consumption (for details, please also see the survey design included in the supplementary material with Tables S4, S5, and S6).

The choice experiment method, a stated preference approach by Louviere and Hensher (1982) and Louviere and Woodworth (1983), was employed in surveys 1-3. The mixed logit model suggested by Revelt and Train (1998) was employed in our analysis to quantify people's preferences, which enables us to consider heterogeneity in preferences and to relax restrictions of independence of irrelevant alternatives. The coefficients for variables and the WTP for the energy technology options were estimated as discussed in national energy preference analysis for residents of Tokyo Metropolitan area (Nakai et al. 2018).

\section{Results and discussion}

\section{Technology assessments with co-learning for regional transformation}

The events and co-learning opportunities at Tanegashima are schematically shown in Fig. 2 and described in Fig. S2 and Table S2. Through these co-learning opportunities
Fig. 2 Phases and co-learning opportunities at Tanegashima. The rounded rectangles show the activities of industry, public organization, and universities or research organization, which are drawn by dotted, dot-dash, and solid lines. The double solid lines mean the activities collaborated by all these three players

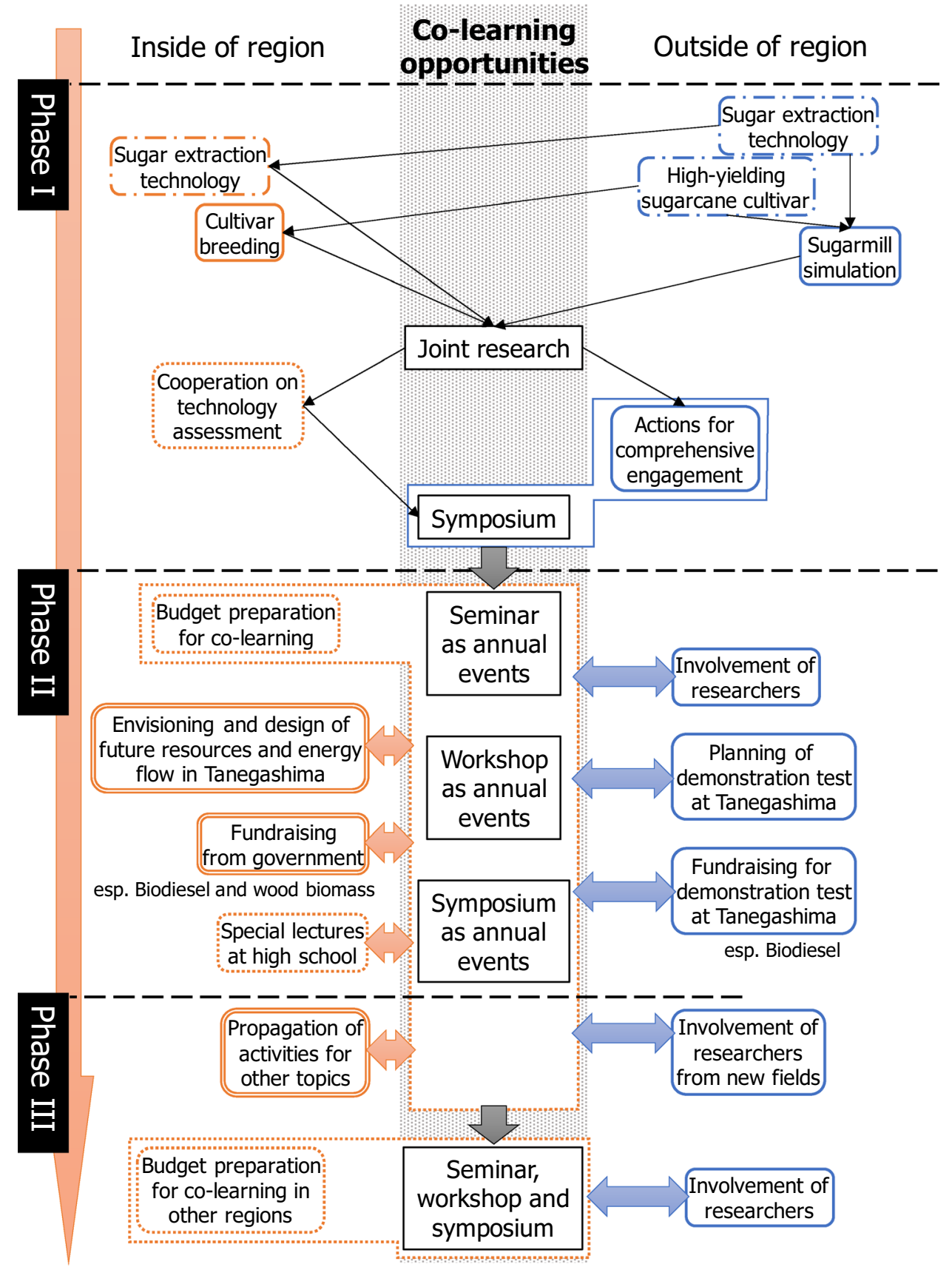


at Tanegashima, the effects of intervention by technology implementation into regional systems were visualized for stakeholders as the result of technology assessments, enabling the agreement of values and relevance on technology implementation among stakeholders. There were the phases of co-learning based on the depth of public engagement and the embeddedness of such opportunities. At the beginning of the Tanegashima case in 2012, the players for regional transformation were only the engineers and researchers in the sugarcane industries in phase I of Fig. 2 (see also Table S8 for the core players). No university campuses, laboratories, or facilities exist in Tanegashima. The topic of the first colearning opportunities on Tanegashima was technology implementation at the sugar mill. The applicability of generated candidate systems in the sugar mill, i.e., high-yielding sugarcane cultivars, was analyzed (Ohara et al. 2009) with selective fermentation (Ohara et al. 2012) based on past demonstration tests in another area (Ohara et al. 2018). The results show that increasing the production of sugarcane can increase the raw sugar exported from Tanegashima and that starting molasses-derived ethanol production can decrease the fossil resources imported to Tanegashima (Ouchida et al. 2017). Those results, related to the revitalization of sugarcane industries, a core of culture on Tanegashima, have become the transition narratives in Tanegashima and have motivated the additional analyses on locally available biomass resources, such as residues from forestry used for fuel during the nonsugar season (Kikuchi et al. 2016a). Such resources from the primary industries necessitate collaborations between public organizations, such as the agricultural and forestry cooperatives. To involve these stakeholders, seminars and workshops were conducted. The demonstration experiments of selective fermentation simultaneously started at the sugar mill, becoming one of the catalysts motivating and involving them as one of the players. After envisioning the roles of the sugar mill in the future Tanegashima, a symposium could be held on Tanegashima involving all municipalities and local industries, including the sugar mill; public organizations, such as the agricultural and forestry cooperatives; and general residents (see also Table S2 for the co-learning communities).

Table 3 organizes the information exchanged between stakeholders and researchers through co-learning opportunities during phases I and II. For the embeddedness of the co-learning opportunities, symposiums, workshops, and seminars were conducted over the last 5 years on Tanegashima (Table S2) by the budget preparation for such colearning opportunities by municipalities during the phase II of Fig. 2. During these co-learning opportunities, the management capacity of municipalities has also been built in cooperation with regional industries, public organizations, and university researchers (Table S8). Consequently, the envisioned material and energy flows were obtained as shown in Fig. 3 as the concept of regional resource circulation, and they can be the starting of co-design of research needs on a systematic analysis of future Tanegashima. The exchanged information was divided into theory, data, and narrative (Table 3). The concerns on regional resources and revitalization were addressed by the proposals of demonstration and the envisioned future systems in Fig. 3. The settings in technology assessments have been affected by this envisioned material and the energy flows to address the concerns on data and narrative, which were also exchanged through co-learning opportunities. Actual benefits from technology implementation and adverse influence on current systems were concerned for regional stakeholders before regional transformation. The practicability of novel technology options has become issues for researchers who cannot play the role of their regional operators. The preference of energy sources is also important to interpret the results of assessments, while the cost for biomass-derived energy can be the main concerns of regional stakeholders. The results of technology assessment employed in these exchanges of concerns and ideas organized in Table 3 are described in the following sections. Note that the settings of technology assessments organized in Table 2 have already considered the exchanged concerned and ideas among regional stakeholders and researchers, which are not shown in Table 3.

\section{LCA for clarifying the environmental loads as the changes of material and energy flows}

The results of LCAs for the cane sugar mill applying the energy technology options listed in Table 1 are shown in Figs. 4 and 5. Figure 4 shows that technology implementation could reduce the LC-GHG from Tanegashima, which is annually about $1456 \mathrm{t}-\mathrm{CO}_{2}$ eq/year, i.e., $48.78 \mathrm{~kg}-\mathrm{CO}_{2} \mathrm{eq} /$ (capita.year) and $5.42 \mathrm{GJ}$-fossil/(capita.year). Most of this reduction originates in the saving of diesel for power generation and gasoline for vehicles. Regarding ethanol production, the construction of a new plant is needed and can be an obstacle to technology implementation. The obstacles for their implementation were not so severe because of a standard technology at foreign sugar mills such as in Thailand and could be eliminated by co-learning with the players with the benefits shown in Fig. 4. If the available amount of biomass-based fuel is associated with the stable powergeneration business, the timber supply for sustainable forest management (Kanematsu et al. 2017b) could also become the rational of the scenarios in Fig. 4 to be realized by the development of technologies and infrastructures within Tanegashima with political supporting (Jack et al. 2008).

The technology implementation at the Tanegashima biodiesel production plant has emerged because the biodiesel produced by the conventional alkali catalyst process cannot be applied in the newer types of diesel engines with 
Table 3 Information exchanged between stakeholders and researchers through co-learning opportunities during phases I and II in Fig. 2, where concerns and ideas are provided from (A) regional stakehold- ers or (B) researchers. The consequential outputs from co-learning is shown as the arrow bullets, i.e., $\rightarrow$

\begin{tabular}{ll}
\hline & Concerns \\
\hline Theory & (A) Unsustainable region with low human-resource \\
& availability \\
(A) Difficulties in revitalization towards sustainability & (A) Low competitiveness by increase in fossil resource \\
prices & (A) Actual benefits from technology implementation
\end{tabular}

Ideas and consequences

(B) High availability in biomass resources per capita

$\rightarrow$ Proposals of demonstration tests for novel technology options

$\rightarrow$ Envisioning of material and energy flows achieved by technology implementation (Fig. 3)

(B) Reduction in LC-GHG emission (Figs. 4 and 5) with forest metabolism (Kanematsu et al. 2017a), circulation of nutrition (Ouchida et al. 2016), and profitability in farmers and sugar mill from technoeconomic viewpoints (Ouchida et al. 2017)

$\rightarrow$ Incentivising of stakeholders to become regional players for technology implementation

(A) Adverse influence on the subsidies for sugar

(B) Practicability of novel technology options

\begin{abstract}
IO analysis and questionnaire survey
\end{abstract}

(B) Influence especially on sugarcane industries production

(B) Confirmation from the Ministry of Agriculture, Forestry and Fisheries, Japan to promote the use of unused sugarcane-derived biomass

$\rightarrow$ Relief for future biomass energy systems without regional conflicts

(A) Possible actions in cane sugar industries, e.g., selectable high-yielding cultivar (NiTn18), and minor changes in sugar mill controls

(A) Necessity in reforestation of old forests in Tanegashima by fuelization due to the declining of timber demands

(A) Employment of existing networks for collecting waste cooking oils

(A) Difficulties in conventional biodiesel-production process for newer types of diesel engines

$\rightarrow$ Conducting of demonstration tests for novel technology options

(A) Sugarcane industry, a core of culture on Tanegashima (Fig. 11)

$\rightarrow$ Public engagements of local governments and public organizations

(A) High cost for biomass-derived energy

(B) Increase of circulation of cash flows inside Tanegashima (Figs. 6, 7, 10)

(B) Increase in the cash flows for agriculture and forestry (Figs. 8, 9)

(B) Deficit production of power by KEPCO-Tanegashima (Fig. 7)

$\rightarrow$ Persuasive rational for public engagements of local industries

(A) Preference for sugarcane-derived resources

(Figs. 11, 12)

$\rightarrow$ Centering of sugar mill as the energy sources in Tanegashima as analyzed in the previous research (Kikuchi et al. 2016a)

(B) Sharing understandings through co-learning opportunities

$\rightarrow$ Seminars for public and lectures in high school
(A) Difference in literacy on energy technology options (Fig. 13) common rail direct fuel injection. Without technology improvement, Tanegashima biodiesel production must be terminated and the raw material, i.e., waste cooking oils by existing collecting networks, can result in an unused resource. The ion-exchange resins catalyst process generated as a candidate system can provide a remedy to such a situation by producing high-quality biodiesel, which is empirically applicable to the newer diesel engines. These conditions motivated the players of biodiesel production to conduct the demonstration tests in Tanegashima. The LCGHG (Fig. 5) means that this highly adaptable technology can reduce GHG emissions from Tanegashima, which could 


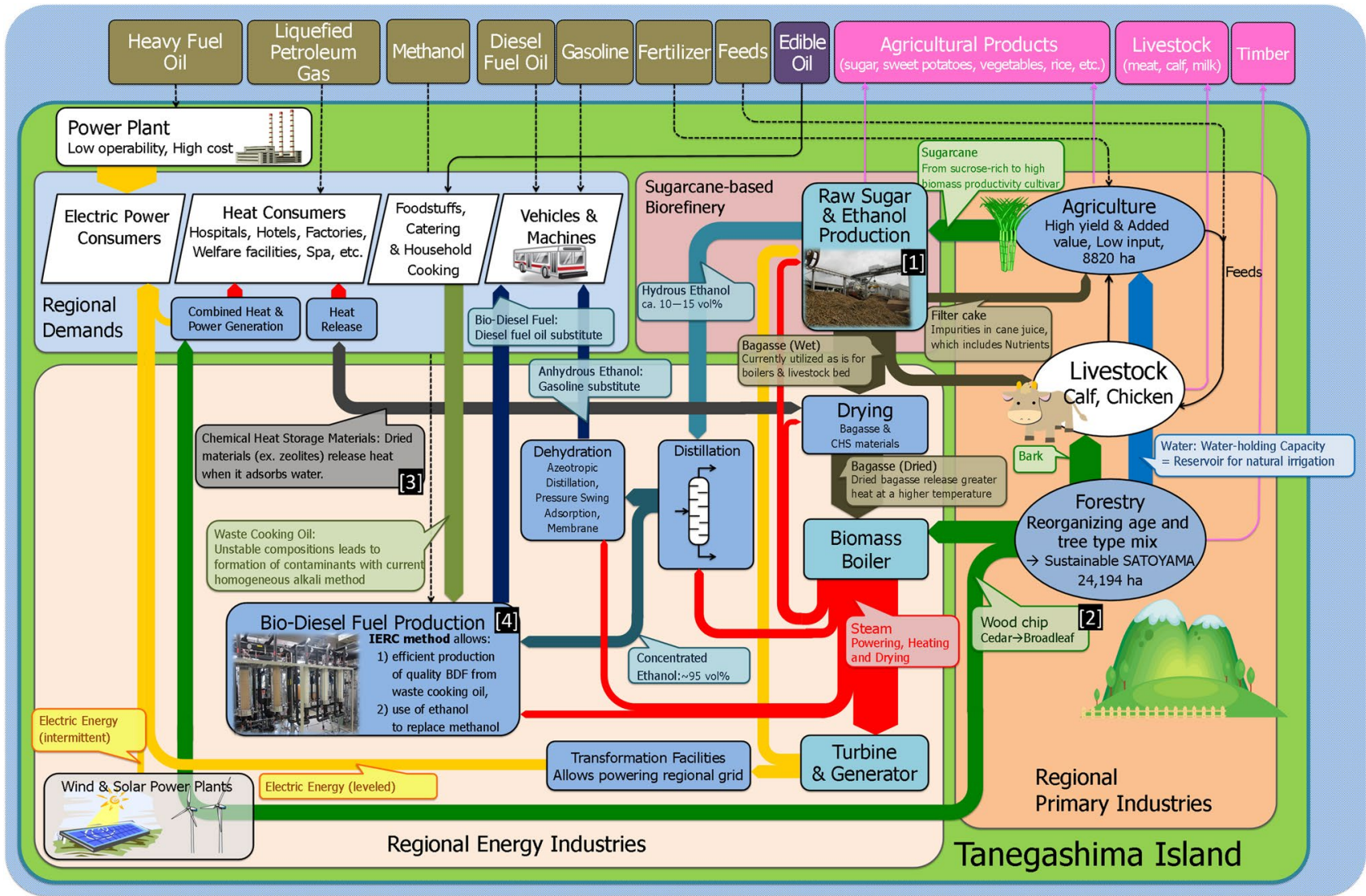

Fig. 3 Envisioned material and energy flows on Tanegashima achieved by technology implementation. The figures in parentheses indicate the technology implementation projects on Tanegashima: [1] sugar mill (Ohara et al. 2009, 2012; Ouchida et al. 2017; Kikuchi et al. 2016a, 2017c); [2] forestry (Kikuchi et al. 2016a; Kanematsu

be used to raise funds from the government. The funds for the demonstration experiments of such biodiesel production could be acquired and are now conducted on Tanegashima.

\section{0 analysis and SPA based on customized 10 table for Tanegashima clarifying the changes in cash flows}

Based on the IO analysis using a customized Tanegashima IO table, the cash flows induced by technology implementation were visualized. Figure 6 shows the Leontief's effects on Tanegashima's internal sectors and its outflows. Comparing Fig. $6 \mathrm{~b}$ with Fig. $6 \mathrm{a}$, the total production inside Tanegashima was increased by 5.13 billion JPY/year, i.e., 0.172 million JPY/(capita.year). A part of this increase is shown in Fig. 7, which largely originates in sugar crop and raw sugar, i.e., $61.5 \%$ and $12.8 \%$ of the total increase, respectively, due to the yield increase resulting from NiTn18. The visualized cash flows of Sugar crop, Silviculture, and Logs through SPA are shown in Fig. 8 (see also Figs. S3 and S4 for their individual diagrams and the trend of calculation et al. 2017a; Oosawa et al. 2016); [3] chemical heat storage (Fujii et al. 2016, 2019); and [4] ion-exchange resin catalyst method of biodiesel fuel production (Chen et al. 2017; Shibasaki-Kitakawa et al. 2010, 2013, 2016)

steps in Eq. 4, respectively). The number of paths in their cash-flow structures was increased as shown in Fig. 8. The magnitude of "Sugar crop" is higher than those of "Silviculture" and "Logs," which can be confirmed by the width of flows in Fig. 8. The newly created sectors contributed to the increase of internal production listed in Table 1, which was represented as the appearing of such sectors in Fig. $8 \mathrm{~b}$ from Fig. 8a. The production of related sectors with the technology implementation on Tanegashima such as road freight transport and agricultural services were also increased. This resulted in a larger increase in the circulation index of "Silviculture" and Logs than for Sugar crop, as shown in Fig. 9. Because sugarcane farming has less connection with other industries within Tanegashima than the other two sectors, its inducing capacity to internal production is less than the other two sectors.

Although the outflows associated with petroleum products decreased (Fig. 10), the increase in chemicals required for agriculture was induced by technology implementation. The inputted petroleum products can be reduced to about 
Fig. 4 LC-GHG emissions related to technology implementation at the Tanegashima cane sugar mill based on the previously developed model for the sugarcane industry (Ouchida et al. 2017) and forestry (Kikuchi et al. 2016a; Kanematsu et al. 2017a, b)
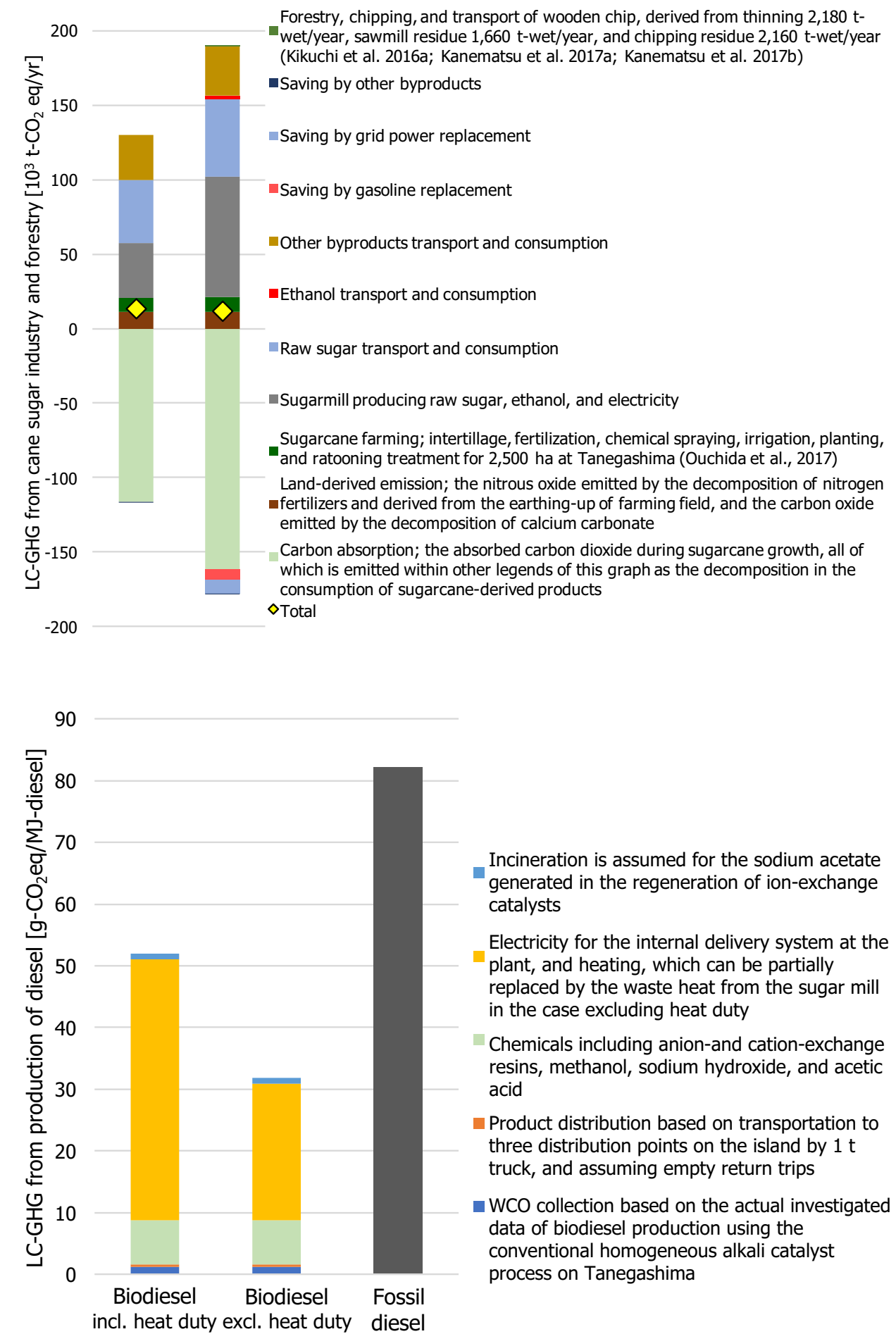

Incineration is assumed for the sodium acetate generated in the regeneration of ion-exchange Electricity for the internal delivery system at the plant, and heating, which can be partially replaced by the waste heat from the sugar mill in the case excluding heat duty resins, methanol, sodium hydroxide, and acetic three distribution points on the island by $1 \mathrm{t}$ data of biodiesel production using the conventional homogeneous alkali catalyst incl. heat duty excl. heat duty diese
Fig. 5 LC-GHG emissions related to biodiesel (fatty acid methyl esters, FAME) production by an ion-exchange resin catalyst process (Chen et al. 2017). In the case of biodiesel excl. heat duty, only the preheating of the mixture of waste cooking oil and methanol, hot water preparation for maintaining the reactors at an adequate temperature, and electricity consumption for heat retention inside the pipes were subtracted by the waste heat from sugarmill (Kikuchi et al. 2016a, b)
$4 \%$ of outflows (Fig. 10). Regarding the induced increases of outflows, the total is about 747 million JPY/year, i.e., 25.0 kilo JPY/(capita.year). The net change of outflow resulted in about 419 million JPY/year, i.e., 14.0 kilo JPY/(capita·year). This result can become an incentive for generating other types of candidates, such as the recovery of nutrients from waste like sewage sludge (Singh and Agrawal 2008). The wages and salaries on Tanegashima were also increased by technology implementation. The total increase of wages and salaries was 409 million JPY/year, i.e., 13.7 kilo JPY/ (capita·year).

Two Tanegashima-specific points are depicted in Fig. 7. The first one is demonstrated in the raw sugar sector. In some countries, not only in Japan, subsidies are currently 


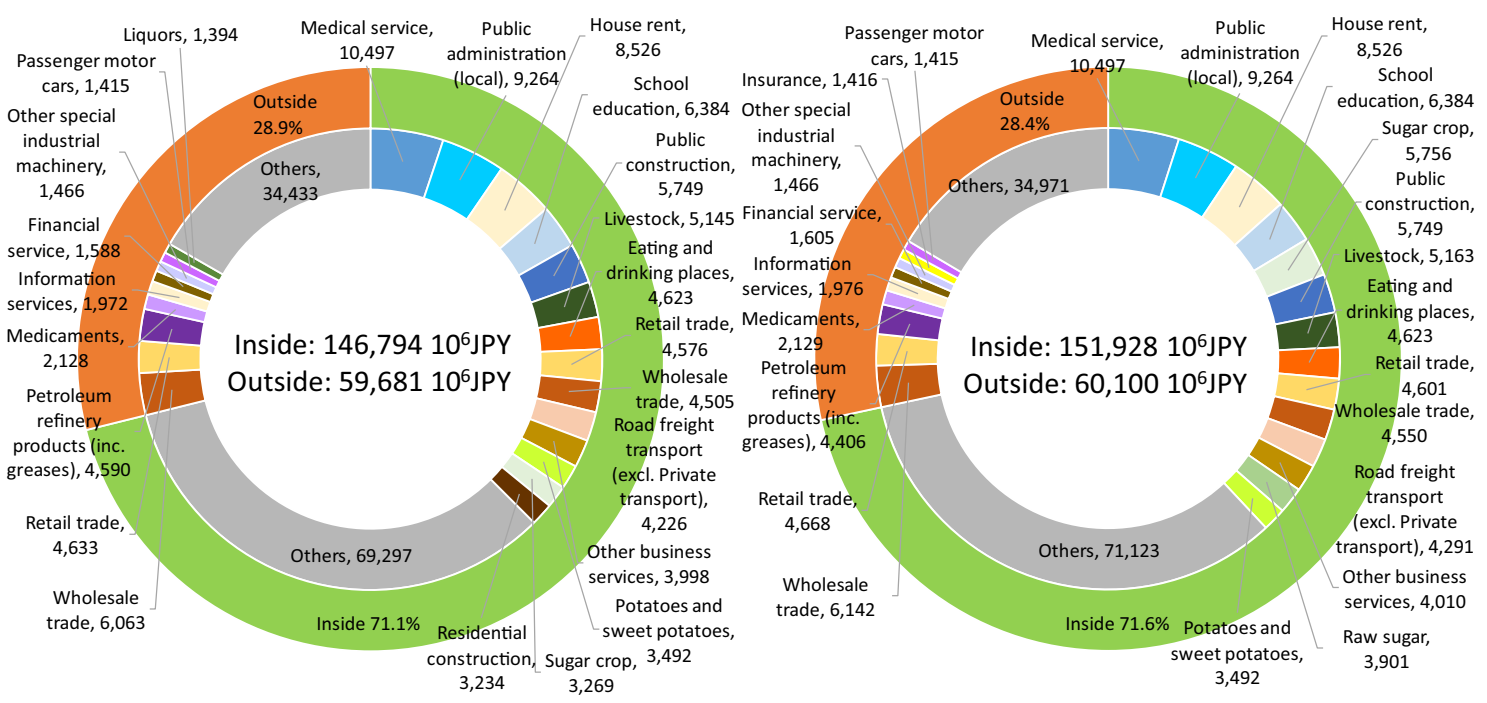

(a) Beforeimplementation

(b) After implementation

Fig. 6 The Leontief's effects on internal sectors of, and the outflows from, Tanegashima. The top 24 and 9 sectors for the before and after technology implementations are depicted. The ratios of sugar crop and raw sugar to all sectors on their production on Tanegashima indicated 1891 times and 884.6 times as many as those of the whole Japan, respectively. The same values were 9.1 times and 22.2 times, respectively, in a comparison between Tanegashima and Kagoshima

$-50 \quad 0 \quad 50100150200250300350 \longleftarrow$

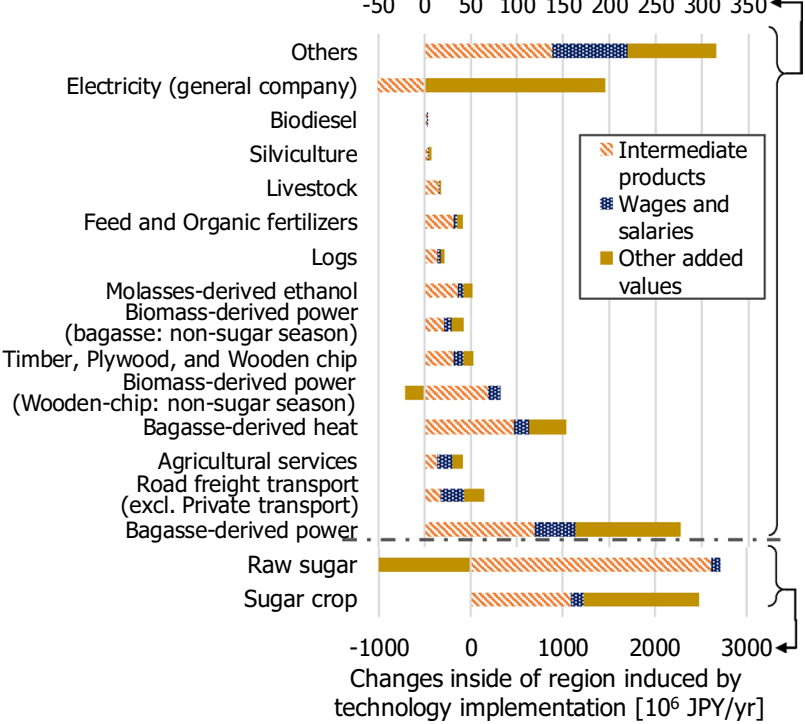

Fig. 7 A part of the results of production changes on Tanegashima induced by technology implementation. The changes are based on the ratio of wages and salaries to total added values in individual sectors. The negative values in other added values in biomass-derived power based on wooden chip, indicate a deficit in power generation, which can be compensated for by bagasse-derived power generation prefecture, where sugarcane industries are relatively more popular than the other prefectures, except for Okinawa prefecture. The changes in total petroleum products are 4.59 billion JPY/year to 4.41 billion JPY/year, the physical amounts of which are gasoline, 9655 $\mathrm{kL} /$ year to $9027 \mathrm{~kL} /$ year, diesel, 13,966 kL/year to $14,550 \mathrm{~kL} /$ year, liquefied petroleum gas (LPG), $5583 \mathrm{t} /$ year (no change), and heavy oil, 51,290 kL/year to $47,285 \mathrm{~kL} /$ year, based on their unit prices

supplied to sugar mills for protecting domestic sugarcane industries from unstable weather conditions. Hence, the other added values of the raw sugar sector in Fig. 7 were negative due to the increase in such subsidies, along with the shipment of sugarcane. This can be recovered by increasing the intermediate products, wages, and salaries. The second point is indicated in the result of electricity by the general power company, i.e., KEPCO in Tanegashima. The generated power from KEPCO was decreased by the transmission of biomass-derived power originating in bagasse and wooden chips. This is shown as negative values in intermediate products, wages, and salaries in Fig. 7. Despite such a decrease in power generation, the other added values were increased. This resulted from the deficit production of power by KEPCO-Tanegashima, which led to the decrease in deficit recovery by whole of KEPCO. This results became an important for involving the general power company in the implementation of biomass-derived power generation on Tanegashima.

\section{Tanegashima residents' energy preferences}

The respondents' individual attributes on their genders and ages, educational backgrounds, and household incomes are listed in Tables S9, S10, and S11, respectively. Tanegashima residents' energy preferences were shown in the resources to be used (Fig. 11), WTP toward power supply (Fig. 12), 


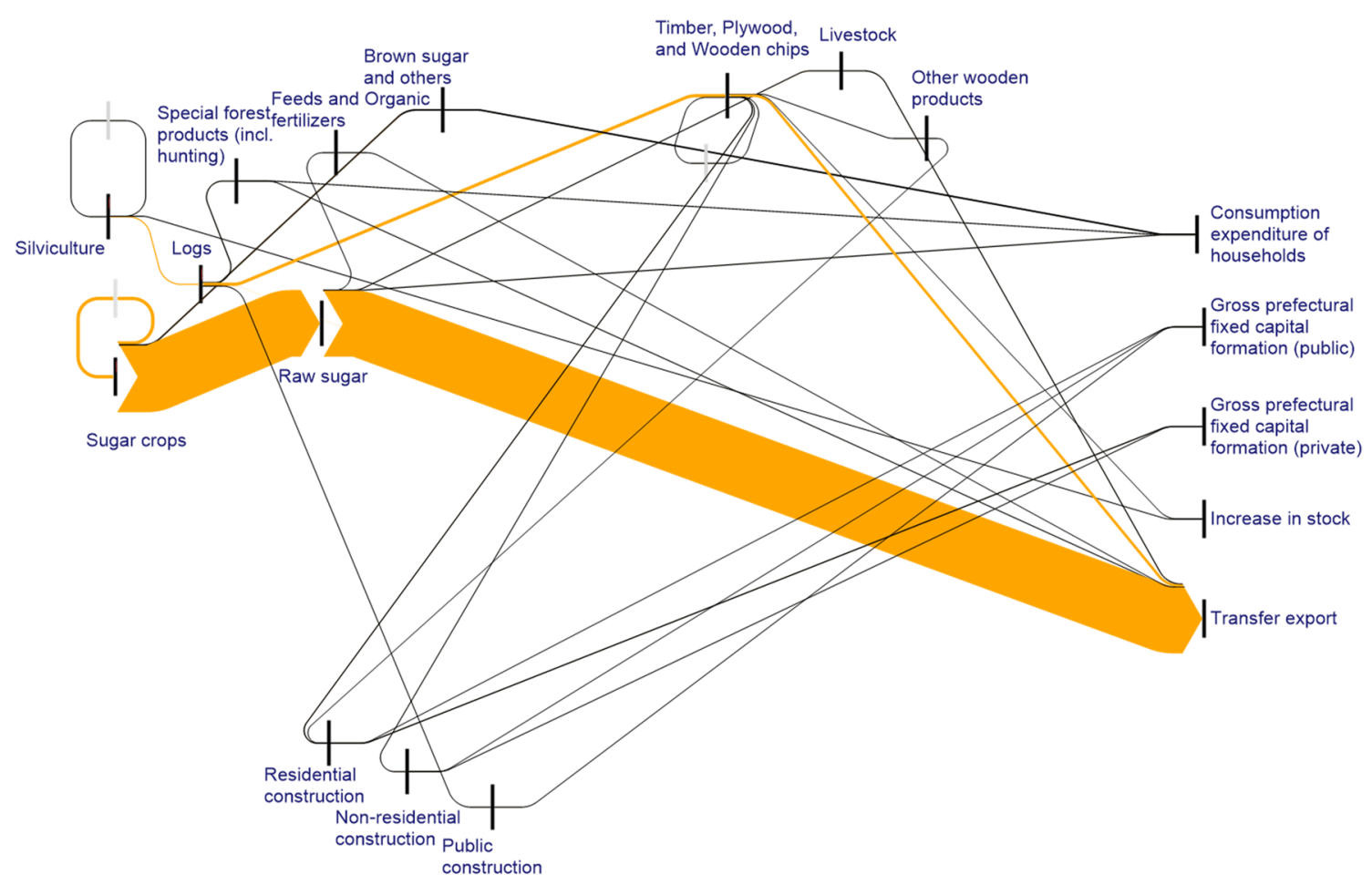

(a) Before technology implementation

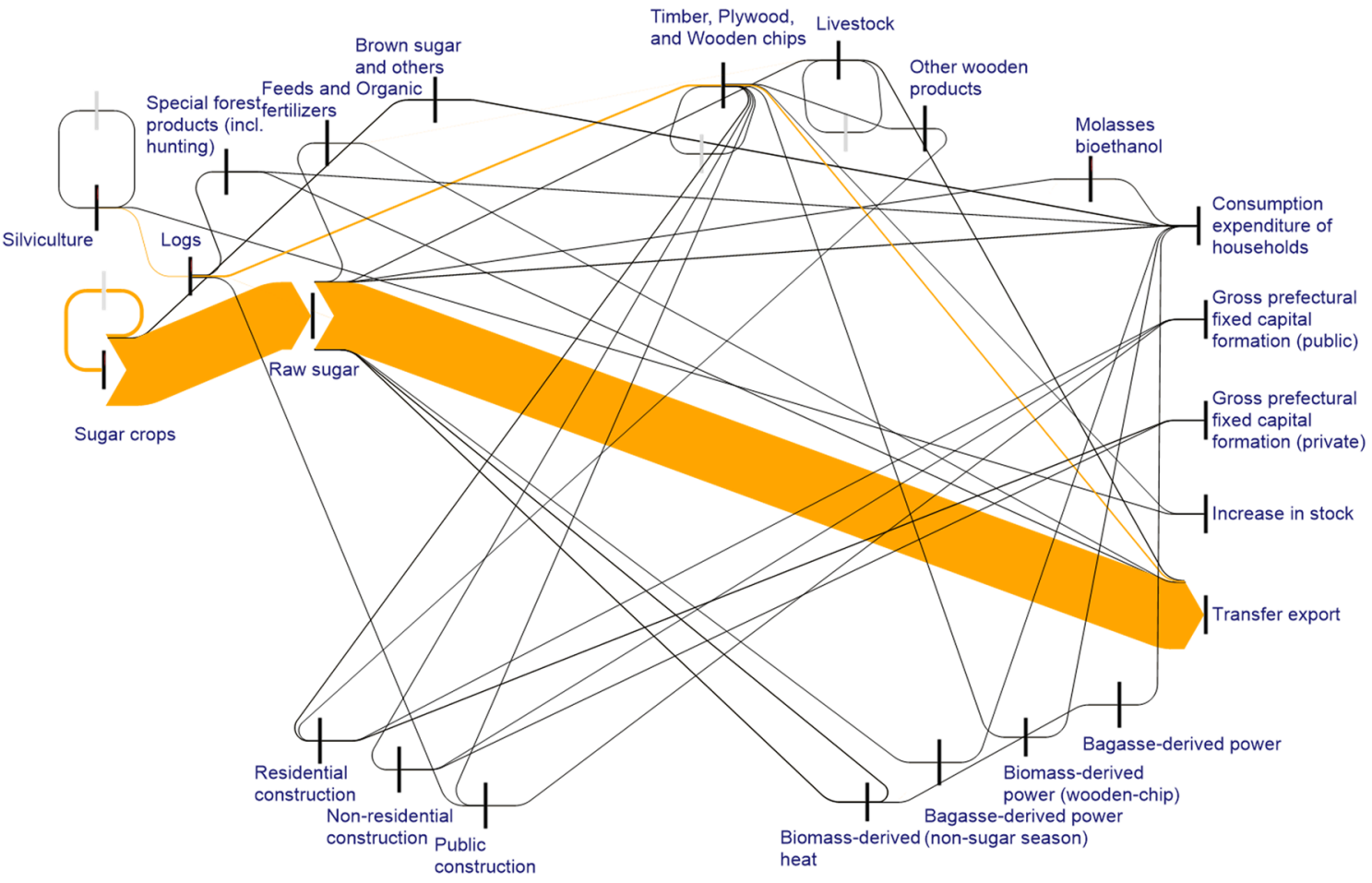

(b) After technology implementation 
4Fig. 8 Cash-flow diagrams of Sugar crop, "Silviculture" and Logs as the paths among sectors, visualized by the SPA based on the Tanegashima customized IO table (see also Fig. S3 for individual flows of Sugar crop, "Silviculture" and Logs)

thermal energy systems to be used (Fig. S5), and the important points to be considered (Fig. S6). Bagasse was selected as the third-ranked resource to be used on Tanegashima (Fig. 11), which is the regional characteristics. Although wooden chips have a large potential on Tanegashima, as well as in the rest of Japan, and is generally selected as the biomass resources to be used for energy systems, it followed the residues from livestock industries, which have become an increasing industry on Tanegashima rather than forestry. Estimation results from the mixed logit model indicates that nuclear power plants are avoided by Tanegashima residents (see Fig. 12), even though no nuclear power plant exists, and they are far from the incidents in nuclear power plants in Japan (Fukushima et al. 2011). Regarding new entries to the power market, foreign companies are not preferred. Although domestic ones are slightly preferred, regional ones are not preferred, which could be due to their low reliability on power supply rather than the general power companies. The same tendencies were observed in the important points to be considered in the decision of energy for residential use (Fig. S6), where the point "No blackout" and "Major provider as the power provider" have relatively more responses. However, increased employment and regional economic circulation were also required (Fig. S5b). According to Fig. S5a, the usability and capital costs were important for the thermal energy facilities. The acceptable payback time was about 7.1 years, calculated as the weighted average based on Fig. S5c.

These preferences should be interpreted as narratives and considered for the motivation and involvement of players. Significant differences in the understanding of residents on the energy technology options should be recognized. The responses on the technology options for hot water systems in survey 4 shown in Fig. 13 revealed such differences. For example, the solar hot water systems are well known by most of the respondents, while some people have never heard of the technology. On the other hand, CHP and DHC were not known as an option on Tanegashima despite the existence of projects on the feasibility study of using DHC in the sugar mill administrated by their municipality. This difference in literacy on technology options can be a cause of misunderstanding and, consequently, uncooperativeness with the regional transformation. Therefore, co-learning with local high school students and residents was examined considering these findings. In particular, high school students have suggested the necessity of technology implementation to local people based on their own surveys and workshops rather than on academic research results, leading to the creation of a situation that enables them to engage in regional transformation.

\section{Embeddedness of co-learning opportunities for regional transformation}

As shown in the previous section and organized in Table 3, the results of the technology assessments have been used in co-learning opportunities and motivate the public engagements in Tanegashima. The information provided by technology assessments was connected with not only the incentives of specific stakeholders such as the increase in the incomes of mills and farmers (Ouchida et al. 2017), but also the certifications from public organizations, such as the Tane-Yaku Agriculture Cooperative and the National Center for Seeds and Seedlings. Such public organizations need public wealth to be associated with the changes. An increase in employment and regional economic circulation can be elements of public wealth, which was analyzed as the socioeconomic aspect of technology implementation using IO analysis (Fig. 7; Kikuchi et al. 2018). The environmental performance, e.g., LC-GHG (Figs. 4, 5), is also essential information for gaining the cooperation of public organizations. The narrative-based involvement of residents and other regional industries can facilitate the creation of consensus to conduct the demonstration tests requiring, more or less, efforts from regional stakeholders, including economic and human contribution. Such efforts can be given from their willingness or preference on energy technology options.

Skilled persons were needed for facilitating co-learning opportunities. The co-learning opportunities could involve multiple fields of research on Tanegashima (Table S8), which are essential for the embeddedness of co-learning. For example, researchers who have expertise studying life cycle thinking are involved in determining the sustainable energy systems (e.g., Wang et al. 2009) to optimize the systems (e.g., Wang et al. 2013). The engagement of the analysts of IO table is also needed to examine the socioeconomic aspects, especially in cash flows with job creation (e.g., Sastresa et al. 2010). Researchers on individuals' preferences are also involved in niche management by deeper engagement of consumers (Seyfang and Haxeltine 2012). The obstacles for municipalities to approve and cooperate in the projects conducted by such skilled persons have been mitigated or removed due to the frequent visits by researchers with their co-learning opportunities, i.e., seminars, workshops, and symposiums. This change in municipalities, which are representative public organizations in a region, is an important element of the ecosystems created for Tanegashima. In other words, the launch of various research projects was a result of the ripple effects of the co-learning opportunities. Involved and motivated players have started to involve other researchers for the projects launched on Tanegashima. 


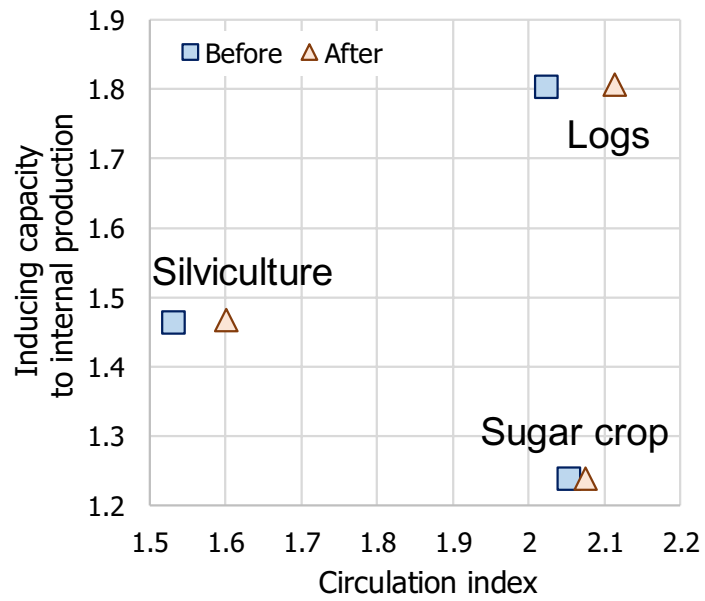

Fig. 9 Changes in the economic circulation on Tanegashima by sectors: circulation index vs. inducing capacity to internal production

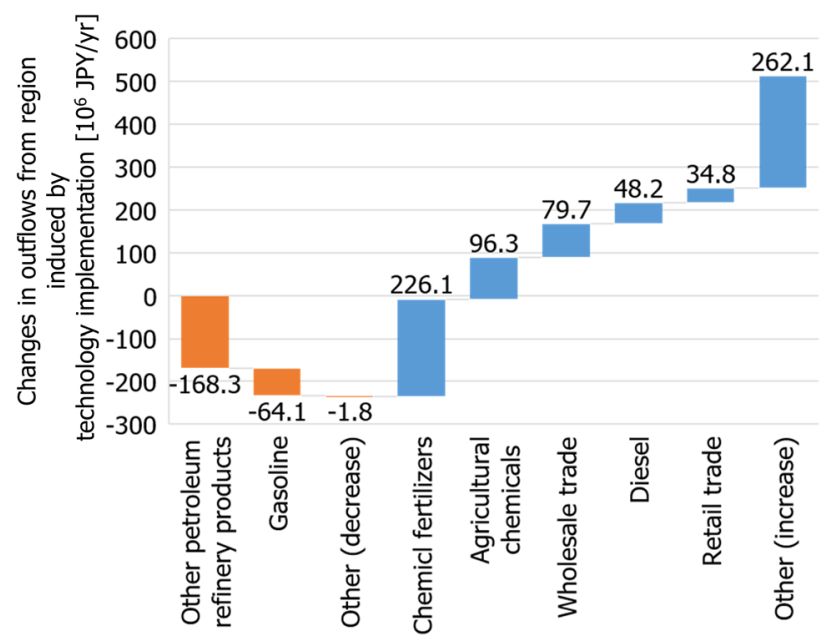

Fig. 10 Changes in outflows from Tanegashima

Another remarkable ripple effect was the changes at the Tanegashima High School. As a result of lectures for the courses listed in Table S2 that serve as education in sustainability (e.g., Barth and Michelsen 2013; Tamura and Uegaki 2012), some of the students have been able to discuss Tanegashima's issues with the Mayor and the city councils, based on their own investigations on the issues and technologies (Nakai et al. 2019). Their commitment to the Tanegashima symposiums (Table S2) has increased. According to a questionnaire survey by the municipality amongst high school students, the responses to the question on life on Tanegashima, "Willingness to live on Tanegashima/Back to Tanegashima someday," increased from $50 \%$ in 2014 to $64.1 \%$ in 2016 , where the survey questions were the same as those presented in ordinary years. The respondents in 2016 were the students who took the lectures and seminars and reported at the symposium in Tanegashima through the

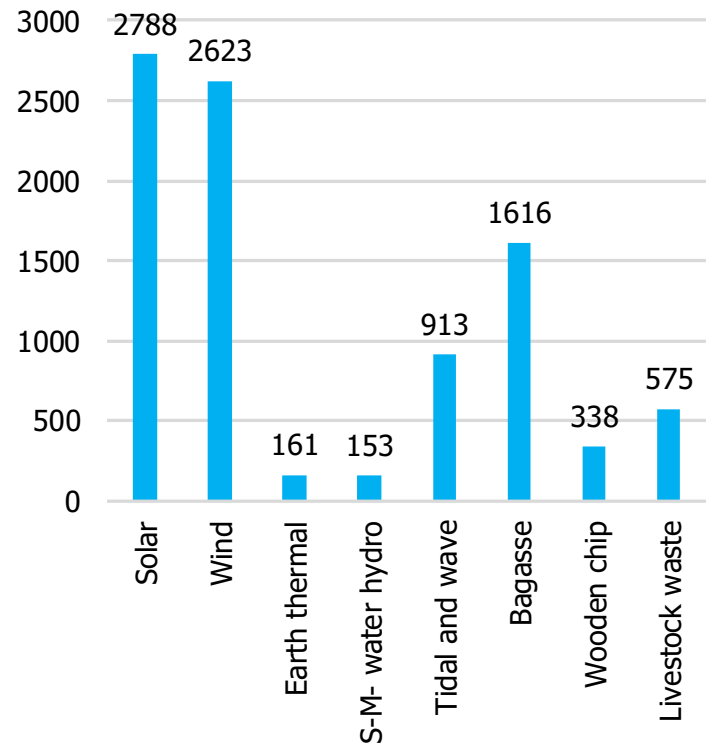

Fig. 11 Preferred resources to be used on Tanegashima. This question appeared in the four surveys listed in Table 2, where a respondent selects three options and some residents responded in Surveys 2 and 4 in Nakatane

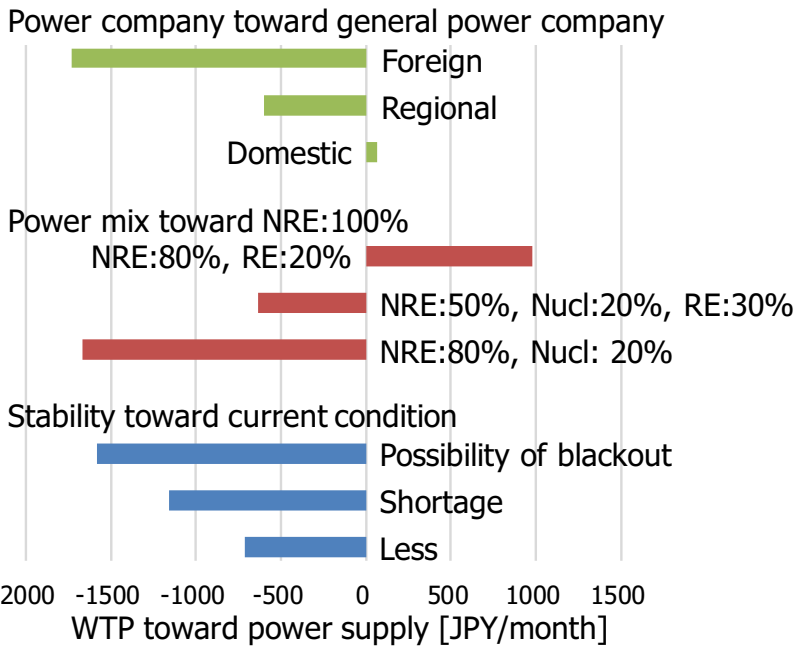

Fig. 12 Willingness-to-pay evaluated for the power supply alternatives on Tanegashima obtained through surveys 1-3, where NRE means non-renewable energy such as fossil fuels, RE represents renewable energy, and Nucl is nuclear energy. The detail settings are presented in Table S4 and Table S5

co-learning opportunities. Tanegashima's co-learning opportunities have the potential to enhance the island's attractiveness for residents.

As shown in phase III of Fig. 2, the researchers from other fields than resources and energy technologies have been involved in Tanegashima, as shown in Fig. S2. A project on health-care systems was also launched as one of the consequences of co-learning communities. As another 


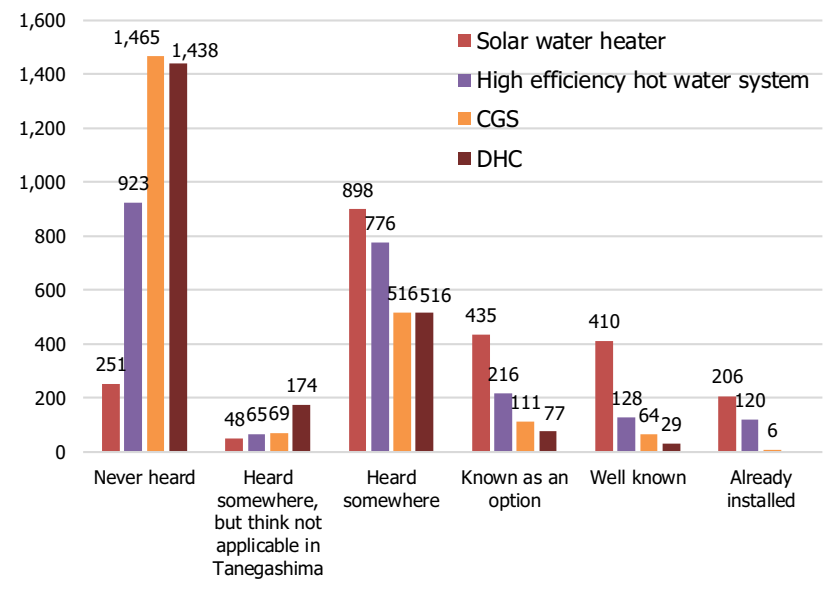

Fig. 13 Acquaintance on the technology options for hot water systems in survey 4. A high-efficiency hot water system is called a Kokoritsu Kyutoki in Japanese, which is a known system based on the recovery of latent heat in the effluent gas. CGS and DHC mean cogeneration systems and district heating and cooling systems, respectively

consequence, the activities for regional transformation with co-learning opportunities have become attractive for other regions such as Okitama of Yamagata Prefecture (Okitama Jikyuken 2018) and the north part of Iwate Prefecture (Iwate Prefecture 2018) in phase III of Fig. 2. The players in these regions were motivated by the achievements in Tanegashima and are involving regional industries and public organizations. Their major common points with Tanegashima are the rural areas where the primary industries are the core of their cultures and relatively higher occupancy within their local economy, although the conditions of weather, climate, and biomass resources to be utilized are different. Local university researchers, however, can be involved in the co-learning opportunities applying technology assessments, providing an advantage over the regions without a university.

\section{Required technology assessments and co-learning for implementing biomass energy systems}

University researchers should facilitate the bridging of gaps between science and the regions by multiple technology assessments on regional biomass energy systems. The analyses of the materials, energy, and cash flows encouraged local governments, industries, and residents to understand technology options through the co-learning opportunities in Tanegashima. According to the rational choice model of cooperation, reputation, trust, and reciprocity are needed before the levels of cooperation (Ostrom 1998). University researchers have a better reputation and may be able to overcome the obstacles of technology implementation as academic research considering the risk/benefit of the transition to unique alternative systems. Conventional local industries are concerned about the disadvantages induced by the changes in local business ecosystems. Newcomers, if any, may not be recognized by the local community as the main entities of the regional system. Thus, the results of flow analyses by university researchers can become plausible reasons for the implementation of new technologies and structures. For the community's trust discussed by Ostrom (1998), university researchers' face-to-face communication among the local community can also lead to obtaining comprehensive information. The reciprocity of technology implementation should also be demonstrated by flow analyses, which must be shared with the related stakeholders to involve them. The Tanegashima case study demonstrated this circulation of reciprocity, reputation, and trust to achieve the robust cooperation between the municipalities, public organizations, and local industries.

The timeline of the changes in Tanegashima shown in Fig. 2 can become a case example of regional transformation by co-learning opportunities described in Fig. S2 and Table S2. Geels and Schot (2007) argue that transitions occur through interactions among niche innovations, sociotechnical regimes, and the sociotechnical landscape. The seeds of niche innovations were generated by university researchers, e.g., the bagasse-derived energy centers at cane sugar mills and novel biodiesel production methods. The windows of opportunity for such seeds of niche innovation are created by the destabilization of regimes such as the deficits in power generation and depopulation indicated as the regional specifications. The landscape, such as the revision of energy-related laws and regulations in Japan, may have placed pressure on the Tanegashima regimes. To grow the seeds of niche innovation, niche actors should be involved and motivated by technology assessments by university researchers, triggering adjustments in existing systems (Geels et al. 2017). Such interactions between researchers and stakeholders are needed for creating the conditions for co-learning (Saint Ville et al. 2015) covering socially and technically complex aspects of technology options (Gillson et al. 2019).

The application of technology assessments into co-learning for regional transformation is inevitable for stakeholders to obtain persuasive proposals of biomass energy systems. Sociotechnical research with model-based analysis (Geels et al. 2017) facilitates the transition by addressing innovation processes, business strategies, social acceptance, cultural discourses, and political struggles based on model-based technical feasibility analyses. However, the regional players' accessibility to such academic disciplines is not always sufficient; therefore, it must be enhanced by sophisticated analyses for the design of regional systems (Komiyama and Takeuchi 2006). The analyses of the materials, energy, and cash flows visualize the effects on the regional systems induced by the implementation of niche innovations and the 
support for communication in the co-learning opportunities, which can offer the communities best-fit technologies based on the analyzed aspects (Coe et al. 2014).

\section{Conclusions}

Multiple technology assessments were applied into colearning for regional transformation to engage the regional public by addressing the concerns of and sharing the ideas for biomass energy systems. Technology assessments were performed on current regional systems and applicable technology options. A case study in Tanegashima demonstrated the actual needs and benefits of co-learning for facilitating the technology assessments. The main questions in this study are whether systematic technology assessments can contribute to the bridging of the valley of death between research development and actual implementation, how the settings of assessment could be defined through co-learning, and how the assessment results could be informative for regional stakeholders. The conclusions are described below.

- The assessment settings could be defined through the colearning opportunities. The regional specifications to be considered as the premises of technology implementation, such as traditional aspects, histories, and cultures, trends of population changes, industrial structures, and energy systems, are sensitive to the progress of technology implementation, and also include the indicators and procedures of technology assessments and the players to be involved. For example, sugarcane industry is one of the cores of cultures in Tanegashima, which is preferred as the local biomass sources. Cultivar breeding and production technology of raw sugar have become a key technology increasing the use of biomass at Tanegashima. Co-learning opportunities have the essential role of exchanging the concerns and ideas which can lead to generate practical settings in technology assessments for learning the regional benefits of technology implementation.

- This study has demonstrated that the holistic incorporation of scientific technology assessments into co-learning can become a fundamental understanding to coordinate the collaboration between researchers and regions. LCA, IO analysis, and choice experiments can be employed as the methods for providing such understandings to be shared with regions as the data proving the benign options in regional systems and for confirming the regional narratives to accept the transformation by implementing the technology options. Their interpretation is needed to examine the technoeconomic, socioeconomic, and sociotechnical aspects of technology implementation.
- The assessment results could become informative through lectures, seminars, workshops, and symposium as co-learning opportunities. The results of scientific assessments were not directly understandable for some of regional stakeholders. Iterative lectures, seminars, workshops, and symposium could lead to the capacity building for them to understand the advantages of and necessitated efforts for technology implementation. The involvement of skilled researchers on system design and assessment was effective in co-learning opportunities as the commentators on their results.

- By the visualization of the multiple aspects of technology implementation, the difficulties for bridging the valley of death could be mitigated. The biomass-based energy technology options need the public engagements in the regions, while PV and WT have less effort during their operation. Additional works for energy systems may be regarded by stakeholders as the cause of higher impacts in cost and environmental impacts rather than conventional systems. LCA and IO analysis applying the regional settings could reveal the actual performances of technology options. Such information can contribute to the bridging of the valley of death in technology implementation.

Regional transformation requires the cooperation of related stakeholders as its players. The proposed co-learning opportunities involve regional outsiders, such as university researchers, in the regional transformation activities. Such academic analyses are needed for placemaking for regional players to join the transformation projects toward sustainability. In addition to such ecosystems involving nonprofit organizations, a sociotechnical system is also needed for constructing business ecosystems for profitable organizations. The themes, i.e., environment, energy, and resources, can be expanded to other regions by referring to the Tanegashima case study. The concept to be achieved in the regions can also be different due to their characteristics, e.g., main crops, main industries, traditional histories, and the willingness of the local society. Alternative technology and system options to be implemented should be generated based on the concept; thus, they should be tested and assessed for obtaining the performance data on the effects of implementation. Even if the performance data and concepts are sufficient, actual implementation needs the transition narratives that should be examined through sociotechnical analysis. Deep implementation of biomass energy systems into local society requires such well-organized concepts, data, and narratives on technology and system options. Through additional case studies on systematic implementation projects of biomass energy systems in regions, open platforms can be designed to coordinate co-learning opportunities, technology assessments, and regional empowerment. 
Acknowledgements Our greatest acknowledgement is given to Dr. Hiroshi Komiyama for the fruitful discussion on the regional innovation and sustainability. The authors acknowledge the support given by Shinko Sugar Mill Company, the Nishinoomote, Nakatane, and Minamitane municipalities, Tanegashima Forestry Cooperative, and Tanegashima-Yakushima Agriculture Cooperative. The authors also acknowledge the core players from inside and outside Tanegashima, Dr. Akira Sugimoto, Dr. Taichiro Hattori, Mr. Takuro Matsuoka, Dr. Satoshi Ohara, Professor Naomi Shibasaki-Kitakawa, Professor Manabu Kano, Professor Takao Nakagaki, Dr. Koichi Fujiwara, Dr. Toshitaka Yamakawa, and Dr. Kotaro Ouchida, Mr. Shoma Fujii. Part of this study was financially supported by the Japan Society for the Promotion of Science (JSPS) KAKENHI Grant number 16H06685 (Research activity start-up), 17K12857 (Young Scientists B), 16H06126 (Young Scientists A), and 15H01750 (Scientific Research A), and the Environment Research and Technology Development Fund (1RF-1503, 3K153014). Activities of the Presidential Endowed Chair for "Platinum Society" in the University of Tokyo are supported by the KAITEKI Institute Incorporated, Mitsui Fudosan Corporation, ShinEtsu Chemical Co., ORIX Corporation, Sekisui House, Ltd., and the East Japan Railway Company.

Open Access This article is licensed under a Creative Commons Attribution 4.0 International License, which permits use, sharing, adaptation, distribution and reproduction in any medium or format, as long as you give appropriate credit to the original author(s) and the source, provide a link to the Creative Commons licence, and indicate if changes were made. The images or other third party material in this article are included in the article's Creative Commons licence, unless indicated otherwise in a credit line to the material. If material is not included in the article's Creative Commons licence and your intended use is not permitted by statutory regulation or exceeds the permitted use, you will need to obtain permission directly from the copyright holder. To view a copy of this licence, visit http://creativecommons.org/licenses/by/4.0/.

\section{References}

Agency for Natural Resources and Energy, Japan (ANRE) (2018) Feedin-tariff for renewable power sources in Japan. https://www.enech o.meti.go.jp/category/saving_and_new/saiene/kaitori/fit_kakak u.html. Accessed 4 Jan 2019

Barth M, Michelsen G (2013) Learning for change: an educational contribution to sustainability science. Sustain Sci 8:103-119. https:// doi.org/10.1007/s11625-012-0181-5

Bouma J (2014) Soil science contributions towards sustainable development goals and their implementation: linking soil functions with ecosystem services. J Plant Nutr Soil Sci 177:111-120. https ://doi.org/10.1002/jpln.201300646

Cabinet Secretariat Japan (2014) Regional employment for Japan's growth-overcoming population decline and revitalizing local economies: Japan's long-term vision and comprehensive strategy. https://www.kantei.go.jp/jp/singi/sousei/info/pdf/panf_eng. pdf Accessed 11 Mar 2018

Cabinet Secretariat Japan (2015) Regional employment for Japan's growth: building local success stories. https://www.japan.go. jp/_userdata/regionalism/A4_12P.pdf Accessed 11 Mar 2018

Chen IC, Shibasaki-Kitakawa N, Ohno H, Fukushima Y (2017) Implementation of a novel biodiesel production system in local community. In: Proceedings of EcoDesign 2017, Tainan, Taiwan

Chen IC, Hiromori K, Kato M, Ohno H, Shibasaki-Kitakawa N, Fukushima Y (2018) A mass-balance-consistent process inventory model for ion-exchange resin catalyzed biodiesel production. $\mathrm{J}$ Chem Eng Jpn (in press)
Coe R, Sinclair F, Barrios E (2014) Scaling up agroforestry requires research 'in' rather than 'for' development. Curr Opin Environ Sustain 6:73-77. https://doi.org/10.1016/j.cosust.2013.10.013

Debois S, Hildebrandt T, Marquard M, Slaats T (2015) Bridging the valley of death: a success story on Danish funding schemes paving a path from technology readiness level 1 to 9 . In: Software engineering research and industrial practice (SER\&IP), 2015 IEEE/ACM 2nd international workshop, pp 54-57. https://doi. org/10.1109/SERIP.2015.18

Domac J, Richards LK, Risovic S (2005) Socio-economic drivers in implementing bioenergy projects. Biomass Bioenergy 28:97-106. https://doi.org/10.1016/j.biombioe.2004.08.002

Ecoinvent (2016) ecoinvent v. 3.3. https://www.ecoinvent.org/login -databases.html. Accessed 4 Apr 2018

Festel G, Würmseher M, Rammer C, Boles E, Bellof M (2014) Modelling production cost scenarios for biofuels and fossil fuels in Europe. J Clean Prod 66:242-253. https://doi.org/10.1016/j. jclepro.2013.10.038

Francis CA, Jordan N, Porter P, Breland TA, Lieblein G, Salomonsson L, Sriskandarajah N, Wiedenhoeft M, DeHaan R, Braden I, Langer V (2011) Innovative education in agroecology: experiential learning for a sustainable agriculture. Crit Rev Plant Sci 30:226-237. https://doi.org/10.1080/07352689.2011.554497

Frederick HH (2011) The role of universities as entrepreneurship ecosystems in the era of climate change: a new theory of entrepreneurial ecology. The Second Entrepreneurship and Management International Conference, Perlis, Malaysia. https://www. academia.edu/30119765/The_role_of_universities_as_entre preneurship_ecosystems_in_the_era_of_climate_change_A new_theory_of_entrepreneurial_ecology Accessed 11 Mar 2017

Fujii S, Kanematsu Y, Kikuchi Y, Nakagaki T (2016) Material and heat flow analysis in thermal energy storage and transport system using unused heat from bagasse boiler. Mech Eng J 3:1600334. https://doi.org/10.1299/mej.16-00334

Fujii S, Horie N, Nakaibayashi K, Kanematsu Y, Kikuchi Y, Nakagaki T (2019) Design of zeolite boiler in thermochemical energy storage and transport system utilizing unused heat from sugar mill. Appl Energy 238:561-571. https://doi.org/10.1016/j.apene rgy.2019.01.104

Fukushima Y, Kikuchi Y, Kajikawa Y, Kubota M, Nakagaki T, Matsukata M, Kato Y, Koyama M (2011) Tackling power outages in Japan: the earthquake compels a swift transformation of the power supply. J Chem Eng Jpn 44:365-369. https://doi. org/10.1252/jcej.11we094

Fukushima Y, Ishimura G, Komasinski AJ, Omoto R, Managi S (2017) Education and capacity building with research: a possible case for future Earth. Int J Sustain High Educ 18(2):263276. https://doi.org/10.1108/IJSHE-10-2015-0170

Fukushima Y, Ohara S (2018) Accounting for the environmental impacts associated with residual products in a comparative life cycle assessment of systems with multiple products. J Environ Sci Sustain Dev 1:1-11. https://doi.org/10.7454/jessd.v1i1.17

Future Earth (2013) Future Earth initial design: report of the Transition Team. International Council for Science (ICSU), Paris, France

Future Earth (2014) Future Earth Strategic Research Agenda 2014. International Council for Science (ICSU), Paris

Geels FW (2006) Co-evolutionary and multi-level dynamics in transitions: the transformation of aviation systems and the shift from propeller to turbojet (1930-1970). Technovation 26:999-1016. https://doi.org/10.1016/j.technovation.2005.08.010

Geels FW, Schot J (2007) Typology of sociotechnical transition pathways. Res Policy 36:399-417. https://doi.org/10.1016/j.respo 1.2007.01.003 
Geels FW, Sovacool BK, Sorrell S (2017) Sociotechnical transitions for deep decarbonization. Science 357:1242-1244. https://doi. org/10.1126/science.aao3760

Gillson L, Biggs H, Smit IPJ, Vira-Sawmy M, Rogers K (2019) Finding common ground between adaptive management and evidencebased approaches to biodiversity conservation. Trends Ecol Evol 34:31-44. https://doi.org/10.1016/j.tree.2018.10.003

Grunewald PH, Cockerill TT, Contestabile M, Pearson PJG (2012) The socio-technical transition of distributed electricity storage into future networks-system value and stakeholder views. Energy Policy 50:449-457. https://doi.org/10.1016/j.enpol.2012.07.041

Hazard L, Steyaert P, Martin G, Couix N, Navas ML, Duru M, Lauvie A, Labatut J (2018) Mutual learning between researchers and farmers during implementation of scientific principles for sustainable development: the case of biodiversity-based agriculture. Sustain Sci 13:517-530. https://doi.org/10.1007/s11625-017-0440-6

Hering JG (2016) Do we need "more research" or better implementation through knowledge brokering? Sustain Sci 11:363-369. https ://doi.org/10.1007/s11625-015-0314-8

Hofstetter P (1998) Perspectives in life cycle impact assessment: a structured approach to combine models of the technosphere, ecosphere and valuesphere. Dissertation ETH No. 12806. ETH Zurich, Zurich, Switzerland. https://e-collection.library.ethz.ch/ view/eth:41276. Accessed 11 Mar 2018

Hondo H, Sadohara S, Hayashi K (2016) Renewable energy-focused input-output table. https://www.hondo.ynu.ac.jp/renewables/resul t/refio.html. Accessed 4 Jan 2018

Ilic DD, Dotzauer E, Trygg L, Broman G (2014) Integration of biofuel production into district heating - part I: an evaluation of biofuel production costs using four types of biofuel production plants as case studies. J Clean Prod 69:176-187. https://doi.org/10.1016/j. jclepro.2014.01.035

Iwate Prefecture (2018) Workshop on regional resource utilization in the north part of Iwate Prefecture. https://www.pref.iwate.jp/seisa ku/suishin/60323/069363.html. Accessed 25 Jan 2019

Jack BK, Kousky C, Sims KRE (2008) Designing payments for ecosystem services: lessons from previous experience with incentivebased mechanisms. Proc Natl Acad Sci USA 105:9465-9470. https://doi.org/10.1073/pnas.0705503104

Jahn T, Bergmann M, Keil F (2012) Transdisciplinarity: between mainstreaming and marginalization. Ecol Econ 79:1-10

Japan Environmental Management Association for Industry (JEMAI) and National Institute of Advanced Industrial Science and Technology (AIST) (2018) Inventory Database for Environmental Assessment (IDEA) v.2. https://idea-lca.com/?lang=en. Accessed 13 Apr 2017

Japan Environmental Management Association for Industry (JEMAI) (2012) LCA software MiLCA version 1.1, JEMAI, Tokyo

Ji X, Long X (2016) A review of the ecological and socioeconomic effects of biofuel and energy policy recommendations. Renew Sustain Energy Rev 61:41-52. https://doi.org/10.1016/j. rser.2016.03.026

Kagoshima Prefecture (2010) Input and output table of Kagoshima Prefecture in 2005. https://www.pref.kagoshima.jp/ac09/tokei/bunya /keizai/renkan/keisu_kako.html. Accessed 4 Jan 2018

Kagoshima Prefecture (2017) Estimated municipal incomes in Kagoshima Prefecture. https://www.pref.kagoshima.jp/tokei/ bunya/keizai/syotoku/index.html. Accessed 4 Jan 2018

Kajikawa Y (2008) Research core and framework of sustainability science. Sustain Sci 3:215-239. https://doi.org/10.1007/s1162 5-008-0053-1

Kanematsu Y, Oosawa K, Okubo T, Kikuchi Y (2017a) Designing the scale of a woody biomass CHP considering local forestry reformation: a case study of Tanegashima, Japan. Appl Energy 198:160-172. https://doi.org/10.1016/j.apenergy.2017.04.021
Kanematsu Y, Okubo T, Kikuchi Y (2017b) Activity and data models of planning processes for industrial symbiosis in rural areas. Kagaku Kogaku Ronbunshu 43:347-357. https://doi.org/10.1252/ kakoronbunshu.43.347

Kato Y, Koyama M, Fukushima Y, Nakagaki T (eds) (2016) Energy technology roadmaps of Japan: future energy systems based on feasible technologies beyond 2030. Springer, Tokyo

Kikuchi Y, Kanematsu Y, Ugo M, Hamada Y, Okubo T (2016a) Industrial symbiosis centered on a regional cogeneration power plant using available local resources: a case study of Tanegashima. J Ind Ecol 20:276-288. https://doi.org/10.1111/jiec.12347

Kikuchi Y, Kanematsu Y, Sato R, Nakagaki T (2016b) Distributed cogeneration of power and heat within an energy management strategy for mitigating fossil fuel consumption. J Ind Ecol 20:289303. https://doi.org/10.1111/jiec.12374

Kikuchi Y, Nakai M, Oosawa K, Kanematsu Y, Ouchida K, Okubo T (2017a) A computer-aided socio-technical analysis on national and regional energy systems considering local availability of renewable resources. Comput Aided Chem Eng 40:2485-2490. https://doi.org/10.1016/B978-0-444-63965-3.50416-5

Kikuchi Y, Oshita Y, Mayumi K, Hirao M (2017b) Greenhouse gas emissions and socioeconomic effects of biomass-derived products based on structural path and life cycle analyses: a case study of polyethylene and polypropylene in Japan. J Clean Prod 167:289-305. https://doi.org/10.1016/j.jclepro.2017.08.179

Kikuchi Y, Ouchida K, Kanematsu Y, Ohara S, Fukushima Y (2017c) Retrofit energy integration for selective fermentation in cane sugar mills under hot/cold energy availability. J Chem Eng Jpn 50:297-308. https://doi.org/10.1252/jcej.16we130

Kikuchi Y, Oshita Y, Nakai M, Heiho A, Fukushima Y (2018) A computer-aided analysis on regional power and heat energy systems considering socio-economic aspects: a case study on an isolated island in Japan. Comput Aided Chem Eng 43:13471352. https://doi.org/10.1016/B978-0-444-64235-6.50236-9

Komiyama H (2014) Beyond the limits to growth. Springer Open, Tokyo

Komiyama H, Takeuchi K (2006) Sustainability science: building a new discipline. Sustain Sci 1:1-6. https://doi.org/10.1007/s1162 5-006-0007-4

Kythreotis AP, Mantyka-Pringle C, Mercer TG, Whitmarsh LE, Corner A, Paavola J, Chambers C, Miller BA, Castree N (2019) Citizen social science for more integrative and effective climate action: a science-policy perspective. Front Environ Sci. https:// doi.org/10.3389/fenvs.2019.00010(article 10)

Kyusyu Electric Power Company, Inc. (KEPCO) (2012) Past records of power demand in Kumage area, KEPCO, Nishinoomote

Kyushu Electric Power Co., Inc. (KEPCO) (2018) A report of the output control on renewable power sources at Tanegashima. https://www.kyuden.co.jp/9437tanega shima5628.html. Accessed 25 Dec 2018

Liew WH, Hassim MH, Ng DKS (2014) Review of evolution, technology and sustainability assessments of biofuel production. J Clean Prod 71:11-29. https://doi.org/10.1016/j.jclep ro.2014.01.006

Life Cycle Assessment Society of Japan (JLCA) (2013) JLCA-LCA database 2013, 1st edn. JLCA, Tokyo

Louviere J, Hensher D (1982) On the design and analysis of simulated choice or allocation experiments in travel choice modelling. Transport Res Rec 890:11-17

Louviere J, Woodworth G (1983) Design and analysis of simulated consumer choice or allocation experiments: an approach based on aggregate data. J Market Res 20:350-367

Luederitz C, Abson DJ, Audet R, Lang DJ (2017) Many pathways toward sustainability: not conflict but co-learning between transition narratives. Sustain Sci 12:393-407. https://doi.org/10.1007/ s11625-016-0414-0 
Lutz LM, Fischer LB, Newig J, Lang DJ (2017) Driving factors for the regional implementation of renewable energy - a multiple case study on the German energy transition. Energy Policy 105:136147. https://doi.org/10.1016/j.enpol.2017.02.019

Lynam T, De Jong W, Sheil D, Kusumanto T, Evans K (2007) A review of tools for incorporating community knowledge, preferences, and values into decision making in natural resources management. Ecol Soc 12:5

Mauser W, Klepper G, Rice M, Schmalzbauer BS, Hackmann H, Leemans R, Moore H (2013) Transdisciplinary global change research: the co-creation of knowledge for sustainability. Curr Opin Environ Sustain 5:420-431. https://doi.org/10.1016/j.cosus t.2013.07.001

Ministry of Internal Affairs and Communications, Japan (MIAC) (2010) Japanese input and output table in 2005. https://www. soumu.go.jp/toukei_toukatsu/data/io/ichiran.htm. Accessed 4 Jan 2018

Moriizumi Y, Hondo H, Nakano S (2015) Development and application of renewable energy-focused input-output table. J Jpn Inst Energy 94:1397-1413. https://doi.org/10.3775/jie.94.1397

Nakai M, Okubo T, Kikuchi Y (2018) A socio-technical analysis of consumer preferences about energy systems applying a simulationbased approach: a case study of the Tokyo area. Energy Res Soc Sci 46:52-63. https://doi.org/10.1016/j.erss.2018.06.004

Nakai M, Kurisu T, Kamizono T, Kakiuchi Y, Okubo T, Kikuchi Y (2019) The impact of workshops on energy literacy and preferences: a case of high school students in Tanegashima island. Nihon LCA Gakkaishi 15(4):343-359. https://doi.org/10.3370/lca.15.343

Neace MB (1995) The marketing-natural environment interface in the classroom: model for discussion. J Market Theor Pract 3:33-37. https://doi.org/10.1080/10696679.1995.11501703

Neves D, Silva CA, Connors S (2014) Design and implementation of hybrid renewable energy systems on micro-communities: a review on case studies. Renew Sustain Energy Rev 31:935-946. https://doi. org/10.1016/j.rser.2013.12.047

Ohara S, Fukushima Y, Sugimoto A, Terajima Y, Idhisa T, Sakoda A (2009) Reduction in greenhouse gas emissions from process retrofitting and cultivar improvement in combined sugar-ethanol production from sugarcane. J Life Cycle Assess 5:439-445. https://doi. org/10.3370/lca.5.439

Ohara S, Fukushima Y, Sugimoto A, Terajima Y, Ishida T, Sakoda A (2012) Rethinking the cane sugar mill by using selective fermentation of reducing sugars by Saccharomyces dairenensis, prior to sugar crystallization. Biomass Bioenergy 42:78-85. https://doi. org/10.1016/j.biombioe.2012.03.024

Ohara S, Terajima Y, Kikuchi Y, Fukushima Y, Yasuhara T, Sugimoto A (2018) Pilot scale demonstration of technologies for enhancing production of sugar and ethanol from sugarcane. Kagaku Kogaku Ronbunshu (in press)

Okinawa Prefecture (2010) Input and output table of Okinawa Prefecture in 2005. https://www.pref.okinawa.jp/toukeika/io/2005/sanren_top. html. Accessed 4 Jan 2018

Okitama Jikyuken (Organization of Okitama towards self-support region) (2018) Regional grand design workshops. https://www.okitamajikyuken.com/. Accessed 25 Jan 2019

Oosawa K, Kanematsu Y, Kikuchi Y (2016) Forestry and wood industry. In: Kato Y, Koyama M, Fukushima Y, Nakagaki T (eds) Energy technology roadmaps of Japan: future energy systems based on feasible technologies beyond 2030. Springer, Tokyo, pp 391-404

Oshita Y, Heiho A, Ouchida K, Kanematsu Y, Fukushima Y, Kikuchi Y (2019) Analyzing socio-economic effect induced by technology implementation on available renewables: a case study of Tanegashima, Japan, Nihon. LCA Gakkaishi 15(4):343-359. https://doi. org/10.3370/lca.15.360

Ostrom E (1998) A behavioral approach to the rational choice theory of collective action presidential address, America Political
Science Association, 1997. Am Polit Sci Rev 92:1-22. https://doi. org/10.2307/2585925

Ouchida K, Kikuchi Y, Okubo T (2016) Integrated modeling of agricultural and industrial processes within life cycle design for environment. Comput Aided Chem Eng 38:1947-1952. https://doi. org/10.1016/B978-0-444-63428-3.50329-5

Ouchida K, Fukushima Y, Ohara S, Sugimoto A, Hirao M, Kikuchi Y (2017) Integrated design of agricultural and industrial processes: a case study of combined sugar and ethanol production. AIChE J 63:560-581. https://doi.org/10.1002/aic.15374

Revelt D, Train K (1998) Mixed logit with repeated choices: households' choices of appliance efficiency level. Rev Econ Stat 80:647-657. https://doi.org/10.1162/003465398557735

Saint Ville AS, Hickey GM, Phillip LE (2015) Addressing food and nutrition insecurity in the Caribbean through domestic smallholder farming system innovation. Reg Environ Change 15:1325-1339. https:// doi.org/10.1007/s10113-015-0770-9

Sastresa EL, Usón AA, Bribián IZ, Scarpellini S (2010) Local impact of renewables on employment: assessment methodology and case study. Renew Sustain Energy Rev 14:679-690. https://doi. org/10.1016/j.rser.2009.10.017

Seyfang G, Haxeltine A (2012) Growing grassroots innovations: exploring the role of community-based initiatives in governing sustainable energy transitions. Environ Plan C 30:381-400

Shibasaki-Kitakawa N, Tsuji T, Chida K, Kubo M, Yonemoto T (2010) Simple continuous production process of biodiesel fuel from oil with high content of free fatty acid using ion-exchange resin catalysts. Energy Fuels 24:3634-3638. https://doi.org/10.1021/ef100109u

Shibasaki-Kitakawa N, Kanagawa K, Nakashima K, Yonemoto T (2013) Simultaneous production of high quality biodiesel and glycerin from Jatropha oil using ion-exchange resins as catalysts and adsorbent. Bioresour Technol 142:732-736. https://doi.org/10.1016/j.biort ech.2013.05.111

Shibasaki-Kitakawa N, Oyanagi T, Borjigin S, Nakashima K, Niwa T, Minami I, Yonemoto T (2016) Pilot-scale production of high quality biodiesel from vegetable oils with high free fatty acid content using ion-exchange resin catalysts. Kagaku Kogaku Ronbunshu 42:30-36. https://doi.org/10.1252/kakoronbunshu.42.30(in Japanese)

Singh RP, Agrawal M (2008) Potential benefits and risks of land application of sewage sludge. Waste Manag 28:347-358. https://doi. org/10.1016/j.wasman.2006.12.010

Stigka EK, Paravantis JA, Mihalakakou GK (2014) Social acceptance of renewable energy sources: a review of contingent valuation applications. Renew Sust Energ Rev 32:100-106. https://doi.org/10.1016/j. rser.2013.12.026

Sugiyama M, Asayama S, Kosugi T, Ishii A, Emori S, Adachi J, Akimoto K, Fujiwara M, Hasegawa T, Hibi Y, Hirata K, Ishii T, Kaburagi T, Kita Y, Kobayashi S, Kurosawa A, Kuwata M, Masuda K, Mitsui M, Miyata T, Mizutani H, Nakayama S, Oyamada K, Sashida T, Sekiguchi M, Takahashi K, Takamura Y, Taki J, Taniguchi T, Tezuka H, Ueno T, Watanabe S, Watanabe R, Yamagishi N, Yoshizawa G (2017) Transdisciplinary co-design of scientific research agendas: 40 research questions for socially relevant climate engineering research. Sustain Sci 12:31-44. https://doi.org/10.1007/s11625-016-0376-2

Tamura M, Uegaki T (2012) Development of an educational model for sustainability science: challenges in the mind-skills-knowledge education at Ibaraki University. Sustain Sci 7:253-265. https://doi. org/10.1007/s11625-011-0156-y

United Nations (2017) The Paris Agreement. https://unfccc.int/paris _agreement/items/9485.php Accessed 14 Apr 2017

Wang JJ, Jing YY, Zhang CF, Zhao JH (2009) Review on multi-criteria decision analysis aid in sustainable energy decision-making. Renew Sustain Energy Rev 13:2263-2278. https://doi.org/10.1016/j. rser.2009.06.021

Wang B, Gebreslassie BH, You FQ (2013) Sustainable design and synthesis of hydrocarbon biorefinery via gasification pathway: integrated 
life cycle assessment and technoeconomic analysis with multiobjective superstructure optimization. Comput Chem Eng 52:55-76. https ://doi.org/10.1016/j.compchemeng.2012.12.008

Weyant JP (2011) Accelerating the development and diffusion of new energy technologies: beyond the "valley of death". Energy Econ 33:674-682. https://doi.org/10.1016/j.eneco.2010.08.008

Wiek A, Harlow J, Melnick R, van der Leeuw S, Fukushi K, Takeuchi K, Farioli F, Yamba F, Blake A, Geiger C, Kutter R (2015) Sustainability science in action: a review of the state of the field through case studies on disaster recovery, bioenergy, and precautionary purchasing. Sustain Sci 10:17-31. https://doi.org/10.1007/s1162 5-014-0261-9

Publisher's Note Springer Nature remains neutral with regard to jurisdictional claims in published maps and institutional affiliations.

\section{Affiliations}

\section{Yasunori Kikuchi $^{1,2}$ (D) Miwa Nakai $^{1} \cdot$ Yuichiro Kanematsu $^{1} \cdot$ Kazutake Oosawa $^{1,3} \cdot$ Tatsuya Okubo $^{1} \cdot$ Yuko Oshita $^{2,4}$. Yasuhiro Fukushima ${ }^{5}$}

1 Presidential Endowed Chair for "Platinum Society", The University of Tokyo, 7-3-1 Hongo, Bunkyo-ku, Tokyo 113-8656, Japan

2 Institute for Future Initiatives, The University of Tokyo, 7-3-1 Hongo, Bunkyo-ku, Tokyo 113-8654, Japan

3 Forestry and Wood Industry Promotions Division, Agriculture, Forestry and Fisheries Department, Wakayama Prefectural Government, 1-1 Komatsubara-dori, Wakayama, Wakayama 640-8585, Japan
4 Faculty of Maritime Sciences, Kobe University, 5-1-1 Fukaeminami-machi, Higashinada-ku, Kobe 658-0022, Japan

5 Department of Chemical Engineering, Tohoku University, 6-6-07 Aramaki-aza-aoba, Aoba-ku, Sendai 980-8579, Japan 